Document downloaded from:

http://hdl.handle.net/10251/66289

This paper must be cited as:

Payri González, F.; Olmeda González, PC.; Martín Díaz, J.; Carreño, R. (2014). A New Tool to Perform Global Energy Balances in DI Diesel Engines 2014-01-0665. SAE International Journal of Engines. 7(1):1-17. doi:10.4271/2014-01-0665.

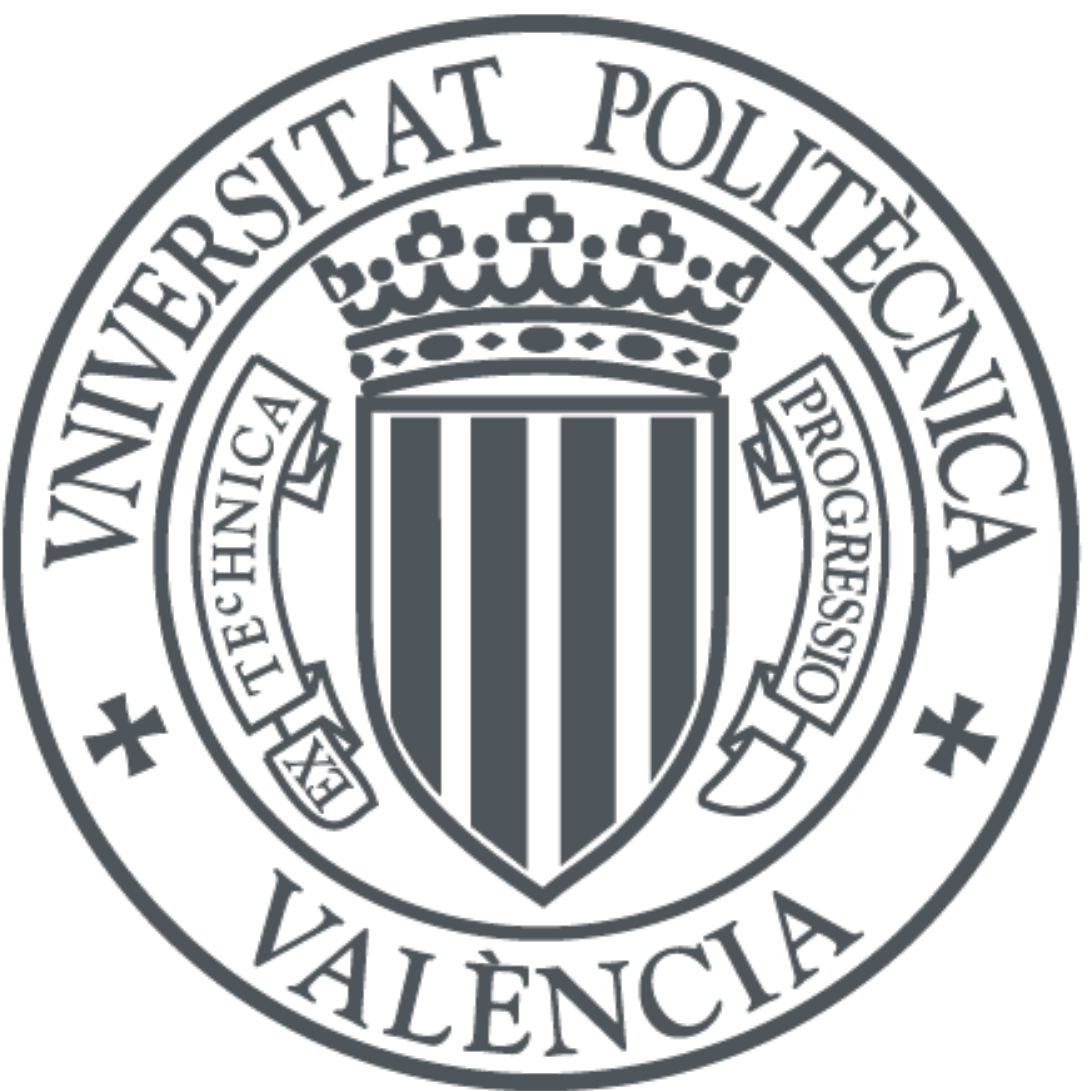

The final publication is available at

http://dx.doi.org/10.4271/2014-01-0665

Copyright SAE International

Additional Information 


\title{
A new tool to perform Global Energy Balances in DI Diesel engines
}

\author{
Francisco Payri, Pablo Olmeda, Jaime Martin, and Ricardo Carreño \\ $\mathrm{CMT}$, Universitat Politècnica de València
}

\begin{abstract}
The generalization of exhaust aftertreatment systems along with the growing awareness about climate change is leading to an increasing importance of the efficiency over other criteria during the design of reciprocating engines. Using experimental and theoretical tools to perform detailed global energy balance (GEB) of the engine is a key issue for assessing the potential of different strategies to reduce consumption. With the objective of improving the analysis of GEB, this paper describes a tool that allows calculating the detailed internal repartition of the fuel energy in DI Diesel engines. Starting from the instantaneous in-cylinder pressure, the tool is able to describe the different energy paths thanks to different submodels for all the relevant subsystems. Hence, the heat transfer from gases to engine walls is obtained with specific convective and radiative models in the chamber and ports; the repartition of the heat flux throughout the engine metal elements towards the oil and coolant is estimated with a lumped capacitance model; finally, the ancillary systems and friction losses are obtained through specific semiempirical submodels. The validation of the tool is performed in a 4cylinder DI Diesel engine instrumented to perform detailed experimental GEB. Finally, a simple analysis of combined internal and external analysis in the complete engine map shows the effect of operating conditions on each energy term. Thus it is demonstrated the utility of the proposed tool, that complements the experimental heat flow measurements in Diesel engine researches oriented to the reduction of energy consumption.
\end{abstract}

\section{Introduction}

Internal Combustion Engines (ICE) are, by far, the most widespread technology to supply energy in the automotive sector. Nevertheless, the success of the ICE has its counterpart, hence the environmental impact of the spread use of ICEs have forced to new regulations that have progressively limited the amount of chemical emission of the vehicles. Thus, in the last two decades the engine research has been mainly focused on reducing the emissions by means of different techniques oriented to limit the pollutant formation during the combustion process or reducing the engine tailpipe emissions. Some of the methods used to optimize the combustion are based on high pressure fuel injection systems [1], multiple injections [2], high boost pressure [3], EGR [4], variable valve timing [5], high swirl ratios [6], new clean fuels [7] or new engine control systems [8]. Nevertheless, the very astringent limits is leading to generalize the use of exhaust gas treatment systems [9] because the possibilities of optimizing the thermofluidynamic processes in the engine to reduce emission formation are not enough to overcome the regulation limits.

Page 1 of 17
This has lead, during the last years, to revitalizing the interest in the other big challenge of the ICE: the engine consumption.

In this scenario, although alternative non ICE-based powertrains are being evaluated, the ICE still has room to increase its efficiency and reduce its Greenhouse Gases (GHG) emissions in traditional or Hybrid Electric powertrains, remaining a cost-effective solution for the transport problem [10]. Hence, the market pressure along with the increasing warning due to the effect of GHG emissions is pushing the researchers and manufacturers to search for more efficient engines with lower consumption and $\mathrm{CO}_{2}$ emissions. The efforts are oriented to different issues such as thermal management [11-14], indicated cycle optimization [15-17], incylinder heat transfer (HT) reduction $[18,19]$, friction and ancillaries losses reduction [20-23] or engine downsizing [24] between others.

To assess the benefits of different engine strategies or configurations, the use of Global Engine Balances (GEB) is a useful tool that allows identifying the repartition of the chemical fuel energy into the final energy destination, thus improving the understanding of which are the main mechanisms affecting the engine consumption. Different works dealing with the GEB can be found in literature, both in $\mathrm{SI}$ and $\mathrm{Cl}$ engines, with conventional or alternative fuels [16,19,25-27]. Usually, the basis of those analyses is the first law of thermodynamics, and, exceptionally, it is combined with an exergy analysis [27, 28]. The most usual approach is to take into account three major terms in the GEB: the brake power, the cooling losses and the exhaust gas losses. A miscellanea term can also be included to consider undetermined energy losses difficult to measure such as convection and radiation to the ambient or HT to the oil $[9,19]$. Thus, in the simplest approach, a very limited number of variables are required to carry out the GEB. However, many term that are not considered in the simple analysis are needed to perform a detailed GEB, hence it is interesting to include specific terms for the heat flow to the oil, heat flow in the intercooler or EGR cooler, or decompose the effect of different mechanical losses; in summary, considering a global methodology that allows analyzing the path followed by the different energy terms, starting from the fuel energy, and detailing the energy degradation due to the different heat and mechanical losses up to the final destination.

This approach includes internal and external analysis of the engine, and requires the use of both experimental measurements and internal modeling of the engine. However, very few works has been found in the literature survey where these different approaches were combined to provide a complete GEB description. Thus, it can be found in the literature: 
- $\quad$ Some works dealing with the experimental approach from the external point of view: in $[16,19,25,26]$ GEB is performed, with different level of complexity, measuring the different fluids temperatures and mass flows along with the engine torque and speed. In some cases [16], the in-cylinder pressure allowed calculating the mechanical and pumping losses.

- A lot of works dealing with the calculation of the HT in the cylinder chamber $[18,19,29-32]$ and detailed finite elements models or lumped conductance models [3335] to estimate the wall temperatures and the heat fluxes repartition.

- Several works describing detailed friction model to estimate the friction in the piston assembly, crankshaft bearing and valve train along with the power to drive the ancillaries system [20-23].

However, no work has been found in the literature where the detailed models of in-cylinder HT, HT throughout the metal parts, friction and ancillaries losses are linked to provide a detailed description of the GEB. The tool described in this work, which is called CALMEC, is focused on the internal analysis of the engine and deals with all the relevant engine subsystems involved. It includes a combination of physical and semi-empirical submodels that are fast and simple enough to be linked with the in-cylinder combustion analysis, thus providing a description of the internal subsystems that, in combination with the external thermal flow measurements, provides a detailed information of the effect of different operating conditions on energy repartition.

\section{Experimental setup}

The submodels adjustment and the parametrical studies were conducted in the experimental setup shown in Fig. 1. The experimental tests were carried out in a 4-cylinder 1.6 litre DI Diesel engine, Euro 5 compliant (Engine 1), that is currently in production. The engine main characteristics are given in Table 1.

The engine was directly coupled to an electric dynamometer that allows controlling the engine speed and load, while the installation includes a complete instrumentation to measure different fluid temperatures and mass flows for external thermal balance. The list of the relevant instrumentation is given in Table 2. A combination of thermocouples and thermoresistance sensors was selected (taking into account the expected temperature variation) to measure liquid and gas temperatures. In the sake of accuracy, the original oil circuit was modified so that the oil was cooled with an external water circuit and a turbocharger oil conditioner was used for controlling the temperatures and oil mass flow of the turbo. Thus, the heat flow to the oil in the block can be measured separately from coolant and turbo oil heat flows.

Table 1.Main characteristics of the engine.

\begin{tabular}{|c|c|}
\hline Displaced volume & $1560 \mathrm{cc}$ \\
\hline Stroke & $88.3 \mathrm{~mm}$ \\
\hline Bore & $75 \mathrm{~mm}$ \\
\hline Connecting Rod & $136.8 \mathrm{~mm}$ \\
\hline Compression ratio & $16: 1$ \\
\hline
\end{tabular}

Page 2 of 17

\begin{tabular}{|c|c|}
\hline Number of cylinders & 4 \\
\hline Inlet valves & 1 \\
\hline Exhaust valves & 1 \\
\hline Injection system & Common rail \\
\hline
\end{tabular}

Table 2.Test cell instrumentation.

\begin{tabular}{|c|c|}
\hline $\begin{array}{c}\text { Temperature of liquids (coolant, oil, } \\
\text { cooling water at exchangers... }\end{array}$ & Termoresistance \\
\hline $\begin{array}{c}\text { Temperature of gases (inlet and } \\
\text { exhaust lines, EGR...) }\end{array}$ & Termocouples \\
\hline Fuel mass flow & AVL 733S Fuel meter \\
\hline Air mass flow & Sensiflow \\
\hline Turbo oil mass flow & Krohne Optimass 3050C \\
\hline Coolant flow & Krohne 4010 Optiflux \\
\hline Oil exchanger cooling water & Isoil MS500 \\
\hline Fuel exchanger cooling water & Yoko AdmagAE208MG \\
\hline
\end{tabular}

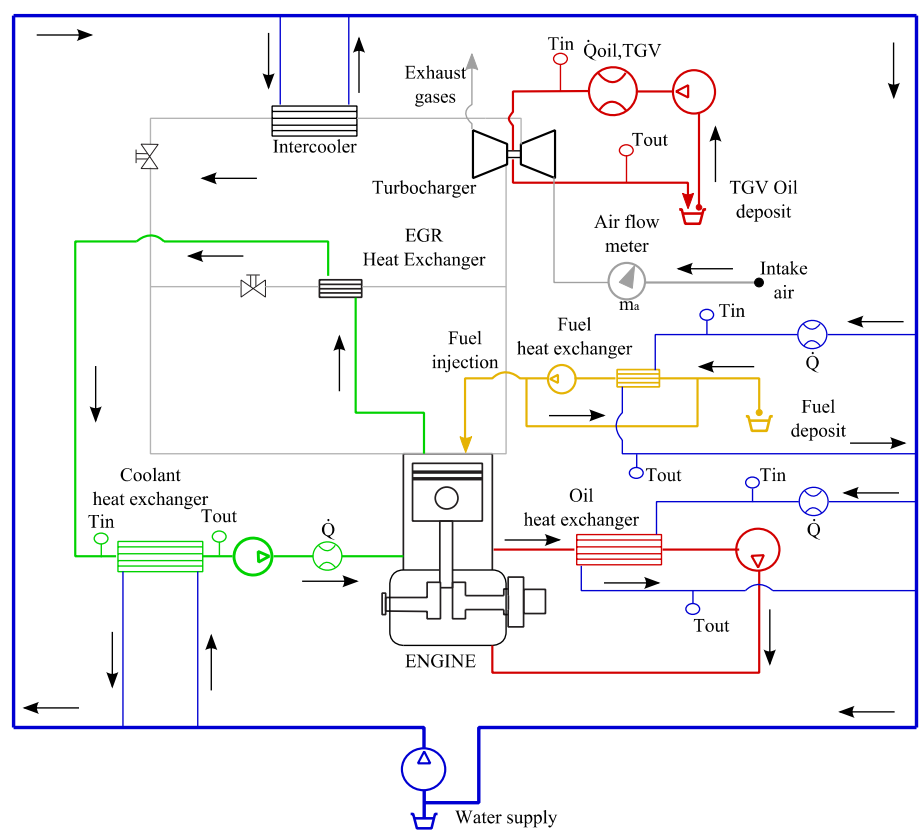

Figure 1. Experimental setup.

The in-cylinder pressure was measured at the 4 cylinders by means of AVL GH13P glow-plug piezoelectric transducers with a range between 0 and 250 bar, and a sensitivity of $16 \mathrm{pC} / \mathrm{bar}$. The electrical charge yielded by the piezoelectric transducers is converted into a proportional voltage signal by means of some Kistler 5011B charge amplifiers. A crank angle increment of $0.5^{\circ}$ was used for the in-cylinder pressure acquisition, which was performed using a Yokogawa DL708E oscillographic recorder with a 16 bits A/D converter module.

The mean variables were acquired at a low sample frequency of $100 \mathrm{~Hz}$ using SAMARUC, a home-developed test system, which collects the signals of different sensors and controls the electric dynamometer. The exhaust emissions were measured 
by a Horiba MEXA 7100 DEGR. EGR flow rate estimation was inferred on the basis of the intake and exhaust $\mathrm{CO}_{2}$ concentrations.

The adjustment of the lumped model that will be described was performed in a second unit of the stated engine (Engine 2), Euro 4 compliant, with similar geometric characteristics to Engine 1. In his case, the metal temperature was measured with 16 thermocouples in the cylinder-head, 23 in the cylinder liner and 2 thermo-resistances in the piston [33].

\section{Global Energy Balance in a DI Diesel engine}

Taking into account all the energy transformations that can take place in a DI Diesel engine, Fig. 2 shows the energy flows that were considered, from two points of view: internal and external analysis.

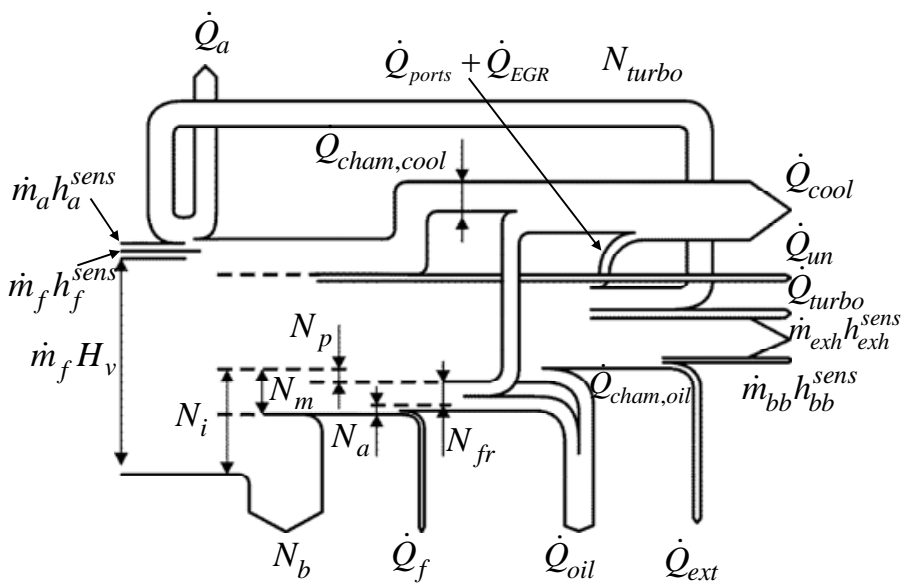

Figure 2. Schema of the energy flows considered.

\section{External GEB}

In this analysis the engine is seen as a black box with some energy flow entering and some other leaving the engine. The main characteristic of this approach is the possibility to measure almost all the energy terms.

The energy flows entering to the engine are the sensible enthalpy of air and fuel, $\dot{m}_{a} h_{a}^{\text {sens }}$ and $\dot{m}_{f} h_{f}^{\text {sens }}$, that depend on inlet temperatures of both fluids, and the chemical energy of the fuel heating value, $\dot{m}_{f} H_{v}$. The main outlet energy flows are the brake power, $N_{b}$, the heat flow to the coolant, $\dot{Q}_{c o o l}$, the sensible energy of the exhaust gases, $\dot{m}_{\text {exh }} h_{\text {exh }}^{\text {sens }}$, the heat flow removed in the oil exchanger, $\dot{Q}_{o i l}$, and the heat flow from the intercooler, $\dot{Q}_{a}$; other outlet terms with lower importance are the HT to the turbo oil, $\dot{Q}_{\text {turbo }}$, the convective and radiative HT to the ambient from the engine surface, $\dot{Q}_{\text {ext }}$, the entalphy flow due to blow-by losses that is externally collected, $\dot{m}_{b b} h_{b b}^{\text {sens }}$, the energy losses due to uncomplete combustion, $\dot{Q}_{u n}$, and finally the small term, $\dot{Q}_{f}$ corresponding to the heating of the fuel returning to the tank, that usually is neglected. The electrical system of the engine is connected to an external power source, so there is no additional energy interchange with the engine.

Page 3 of 17
The stated terms account for the external GEB of the engine and can be measured using the experimental instrumentation described in the previous section. Thus, $N_{b}$ is computed from engine torque and speed, the enthalpy flows can be obtained from the mass flow of the gases and its temperatures, $\dot{Q}_{c o o l}$, $\dot{Q}_{\text {oil }}, \dot{Q}_{\text {turbo }}, \dot{Q}_{a}$ and $\dot{Q}_{f}$ from the fluids mass flows and the temperature increment, $\dot{Q}_{\text {un }}$ can be estimated from the CO and $\mathrm{CH}$ emissions in the exhaust, and finally $\dot{Q}_{\text {ext }}$ is obtained from the difference of the rest of measured terms. Hence, the thermal balance can be written as

$$
\begin{aligned}
\dot{m}_{f} H_{v}= & N_{b}+H_{e x h}+\dot{Q}_{c o o l}+\dot{Q}_{o i l}+\dot{Q}_{a}+\dot{Q}_{t u r b o}+\dot{Q}_{u n}+ \\
& +\dot{Q}_{e x t}+\dot{Q}_{f}+H_{b b}
\end{aligned}
$$

being

$H_{\text {exh }}=\dot{m}_{\text {exh }} h_{\text {exh }}^{\text {sens }}-\dot{m}_{a} h_{a}^{\text {sens }}+\dot{m}_{f} h_{f}^{\text {sens }}$

where $h_{\text {exh }}^{\text {sens }}, h_{a}^{\text {sens }}$ and $h_{f}^{\text {sens }}$ are the sensible enthalpies of the exhaust gases, inlet air and fuel (calculated at their respective temperatures) and $\dot{m}_{e x h} \approx \dot{m}_{a}+\dot{m}_{f}$. In the sake of rigour, the blow-by mass $\dot{m}_{b b}$ should be removed from $\dot{m}_{e x h}$, however, in all tested operating points the blow-by was lower to $1.5 \%$ of $\dot{m}_{a}$, thus it was neglected in a first approach. Analogously, the term $H_{b b}$, which accounts for the net enthalpy flow due to the blow-by, was not taken into account, as it was estimated that in all the operating points it is lower to $0.5 \%$ of the fuel energy $\dot{m}_{f} H_{v}$.

The importance of each term in (1) vary with the engine and operating conditions, however the most important of them use to be in current automotive $\mathrm{Cl}$ engines in the following ranges: $N_{b} \sim 25-40 \%$ (excepting at very low load), the cooling losses $\dot{Q}_{\text {cool }} \sim 15-35 \%$, the exhaust gas losses, $H_{\text {exh }} \sim 20-35 \%$ and the HT to the oil $\dot{Q}_{\text {oil }}$ use to be about one third of $\dot{Q}_{\text {cool }}$.

\section{Internal GEB}

The described external approach to the GEB is straightforward and it can be performed with the usual engine measurement devices. However when the analysis of the internal GEB is performed, terms such as walls HT or mechanical losses can be barely measured, due to the experimental difficulty. To deal with the determination of such energy flows, the available experimental measurement must be combined with models of particular processes and systems $[33,36]$.

The internal GEB includes the following terms: $N_{i}$ (usually ranging $35-40 \%$ of the fuel energy) is the indicated power which is split in different terms whose importance depends on the operating conditions; thus, part of it provides the brake power, part the pumping work, $N_{p}$, and finally, part is lost due to the friction, $N_{f r}$, and to drive the engine ancillaries, $N_{a}$ (fuel, oil and cooling pumps). The total amount of mechanical losses will be:

$N_{m}=N_{p}+N_{a}+N_{f r}$

If a more detailed description of $N_{a}$ and $N_{f r}$ is considered, they can be expressed as: 
$N_{a}=N_{f}+N_{\text {cool }}+N_{\text {oil }}(4)$

$N_{f r}=N_{f r, p i s}+N_{f r, b e a r}+N_{f r, v a l v}(5)$

where $N_{f}, N_{\text {cool }}$ and $N_{\text {oil }}$ are the power to move the fuel pump, the coolant pump and the oil pump and $N_{f r, p i s}, N_{f r, b e a r}$ and $N_{f r, v a l v}$ are the friction losses in the piston assembly, bearing and valves train. The total value of $N_{a}+N_{f r}$ can be computed from net indicated power, $N_{i}-N_{p}$, and brake power, however, obtaining the value of each term included in equations (4) and (5) is not possible through the experimental measurements in the engine. If ancillaries are tested out of the engine and specific test rigs are used to characterize friction losses [23], it is possible to obtain their values, but this is usually not possible. Regarding the relative importance of each term of the mechanical losses, a wide variation range can be found in the literature $[9,23,37]$, thus $N_{b}$ ranges $15-30 \%$ of the total mechanical losses $N_{m}, N_{a}$ is assumed to be $15-25 \%$ of $N_{m}$, and $N_{f r}$ about $45-65 \%$ of $N_{m}$. The repartition of the terms in $N_{f r}$ is also variable depending on the source: $N_{\text {pis }} \sim 40-75 \%$ of $N_{f r}, N_{\text {bear }} \sim 20-40 \%$ of $N_{f r}$ and $N_{\text {valv }} \sim 7-30 \%$ of $N_{f r}$. Specific submodels to obtain an estimation of each component will be presented in the next section.

Other two important terms in the internal GEB are the HT flows to the coolant and oil. The main contribution to the these terms is the HT from the chamber gases to the coolant $\dot{Q}_{\text {cham,cool }}$ and oil $\dot{Q}_{\text {cham,oil }}$ and in lesser extent the heat flow from ports, $\dot{Q}_{\text {ports }}$ , and EGR to the water, $\dot{Q}_{E G R}$. Finally, friction and ancillaries power are degraded into heat and then shared out to the coolant, oil and ambient. Thus, the friction between the pistonring and the cylinder walls, which account for a substantial part of the friction losses, contributes to increase mainly the coolant energy while the friction in the rest of elements is dissipated to the lubricant oil and the surroundings. Except $\dot{Q}_{E G R}$, that can be directly calculated, the rest of HT terms cannot be measured. Hence, efforts were made for developing accurate chamber HT models, and estimating HT repartition to coolant and oil by means of a lumped conductance model, as detailed in the following section. Finally, in the sake of simplicity, there is also a term that is not explicitly included in Fig. 2, it is the HT from oil to coolant in the block. It cannot be measured and is very difficult to assess by means of modeling, a simple way for its estimation will be later discussed.

Finally, the energy delivered by the turbine to the compressor (throughout the turbo shaft mechanical power and HT) is represented in the schema of Fig. 2 with $N_{\text {turbo }}$. The thermal energy from hot gases to the turbo case and the mechanical friction in the turbocharger shaft are included in the HT to the turbo cooling oil and the convection and radiation to the ambient.

\section{Submodels description}

Taking into account the consideration made in the previous section, different submodels to assess the terms of the internal GEB are proposed here. External thermal measurements will be used later to validate the models.

Page 4 of 17

\section{Heat transfer models}

As mentioned, there are two main sources of $\mathrm{HT}$ in the engine: the combustion chamber and the gases in the exhaust ports. Both of them will be linked with the lumped conductance model.

\section{Convective heat transfer in the chamber}

Heat transfer to the combustion chamber walls in motoring tests (or during the compression stroke and after the end of combustion), is essentially governed by convection, because gas radiation to the walls is negligible in these conditions [29, 30]. When combustion takes place the gas convection keeps on being the key issue, although radiation from the gas and the soot particles becomes also important.

Many different empirical correlations to estimate the HT coefficient, based on the Nusselt approach, are available in literature. Amongst them, those proposed by Annand [29] or Woschni $[31,32]$ are the best known. Starting from a reference model, authors use to adjust the model constants values in their specific engines. In the present model, a variation of the expression proposed by Woschni is used to calculate the HT coefficient:

$h=C D^{-0.2} p^{0.8} T^{-0.53} v_{g}^{0.8}(6)$

where $C=0.12, D$ is the engine bore, $p$ and $T$ are the instantaneous in-cylinder pressure and temperature and $v_{g}$ is the gas speed in the chamber calculated as:

$v_{g}=C_{W 1} c_{m}+C_{W 2} c_{u}+C_{2} \frac{V_{d} p_{I V C}}{V_{I V C} T_{I V C}}\left(p-p_{0}\right)(7)$

where $c_{m}$ is the mean piston speed, $c_{u}$ is tangential velocity due to the swirl, $V_{d}$ is the displaced volume, $p_{I V C}, V_{I V C}, T_{I V C}$ are pressure, volume and temperature at the intake valve closing, $p_{0}$ is the motoring pressure assuming polytrophic evolution, and $C_{W 1}, C_{W 2}$ and $C_{2}$ are constants that must be adjusted. Efforts were done in order to improve the original Woschni model, thus, the values of the original constants have been modified, and the way in which the swirl effect is considered is also different from that proposed by Woschni. The value of the constant of the combustion term, $C_{2}=0.001$, the instantaneous evolution of the swirl velocity, $c_{u}$, (constant in the original Woschni's model) and the ratio $C_{W 1} / C_{W 2}=1.7$ were set by means of CFD calculations in two previous works developed in the research group $[38,39]$. Hence, the only value that must be adjusted to have a complete convective HT model in the chamber is the value of $C_{W 1}$, from which $C_{W 2}$ is obtained assuming the stated ratio between them. Brief description of $C_{W 1}$ adjustment will be later provided.

\section{Radiative heat transfer in the chamber}

There is no agreement with respect to the fraction of the HT that is transferred by radiation: Morel and Keribar [30] obtained values ranging from $4 \%$ to $20 \%$, whereas Heywood [9] states that this fraction can be higher than $20 \%$. In any case, the accurate estimation of radiation in the chamber will require the calculation of the soot formed in the spray [40]. 
Fig. 3 shows an schema of the radiation submodel used to calculate the total radiation power from the soot in the flame $Q_{\text {rad }}$. A combustion model [41] provides a simplified spatial evolution of the fuel parcels in the spray, along with their temperature and mass fraction of air, fuel and burned products. From this information the fuel-to-air equivalence ratio at the liftoff and the residence time of each parcel in the spray is obtained. This information along with the flame temperature and the air density allows computing the soot yield (SY), defined locally as the ratio between the mass fraction of fuel transformed into soot and the mass fraction of unburned fuel available at that location [42]. From the SY, and knowing the fuel mass concentration in the center line of the spray, the soot mass fraction in the centerline is calculated and thus the soot volumetric fraction in the centerline. This soot formation model was adjusted with laser extinction measurement. Once the soot formed is known, the radiation from each parcel in the spray is computed taking into account its temperature, according to the black body radiation, whence the total amount of radiation can be obtained. The radiation model was adjusted using two-color method. A more detailed description of the process, hypothesis and model validation can be seen in [43].

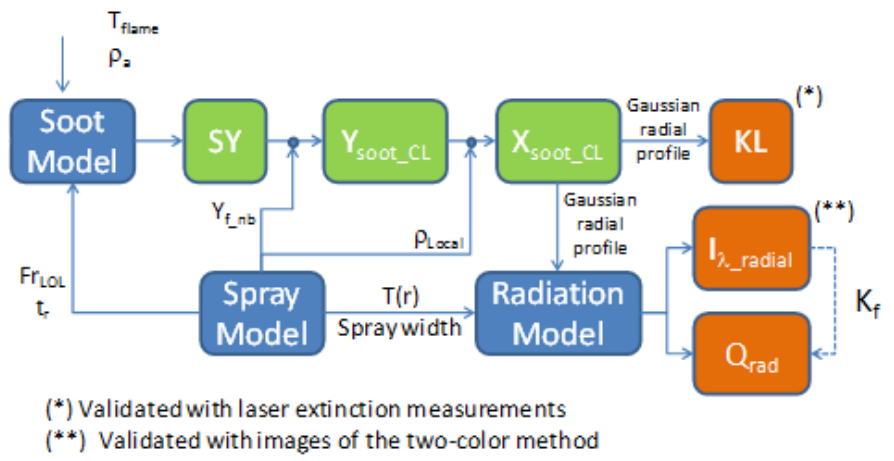

Figure 3. Schema of the radiation submodel.

\section{Heat transfer in the ports}

Intake ports HT use to be negligible in comparison with exhaust ports. In both cases, different semiempirical expressions can be found in the literature [44]. Starting from the Assanis [45] proposal

$\overline{N u}=0.0694 \overline{R e}^{0.75}(8)$

it was assumed that the intake valves diameter, $D_{\text {int }}$, is the characteristic diameter for the calculation of $R e$, and the values of density $(\rho)$, viscosity $(\mu)$, conductivity $(k)$ and velocity $(v)$ in the intake port were time averaged. Thus the following expression for the HT coefficient was derived:

$h_{\text {int }}=0.0694 \overline{k_{\text {lnt }}} \mathrm{D}_{\text {int }}^{-1.75}\left(\frac{\dot{\mathrm{m}}_{\text {int }}}{\overline{\mu_{\text {int }}} \pi}\right)^{0.75}(9)$

where $\overline{k_{\text {tnt }}}$ and $\overline{\mu_{\text {tnt }}}$ are the mean value of the conductivity and dynamic viscosity at the intake ports, calculated as function of the mean inlet gas temperature, and $\dot{\mathrm{m}}_{\mathrm{int}}$ is total intake mass flow, including fresh air and EGR.
In the case of the exhaust ports, following the proposal Dolz [44] the opened and closed cycles were separated because of the differences in the thermodynamic conditions and velocity of the gases. For the closed cycle, starting from the proposal of Caton [46] and assuming analogous considerations to the intake ports, the following expression was derived:

$h_{\text {exh }, \text { closed }}=0.022 \overline{k_{\text {exh }}} \mathrm{D}_{\text {exh }}^{-1.8}\left(\frac{\dot{\mathrm{m}}_{\text {exh }}}{\overline{\mu_{\mathrm{exh}} \pi}}\right)^{0.8}$

where $\overline{k_{\text {exh }}}$ and $\overline{\mu_{\text {exh }}}$ are the mean value of the conductivity and dynamic viscosity at the exhaust ports (function of the mean exhaust gas temperature), $D_{\text {ext }}$ is the exhaust valves diameter, and $\dot{\mathrm{m}}_{\text {exh }}$ the total exhaust mass flow.

A instantaneous HT coefficient was calculated during the opened cycle [47]:

$h_{\text {exh }}(t)=0.00375 k_{\text {exh }}(t) \frac{\rho_{\text {exh }}(t)}{\mu_{\text {exh }}(t)} v_{e x h}(t)$

where the conductivity, $k_{\text {exh }}$, the viscosity, $\mu_{\text {exh }}$, and velocity, $v_{\text {exh }}$, at the exhaust port are instantaneously computed using a simple filling and emptying model [36] and then averaged during the opened cycle.

\section{Lumped heat transfer model}

Finally, the calculation of the heat flux to the walls and its repartition to the coolant and oil requires the estimation of the wall temperatures at different positions. Starting from the proposal in $[33,35]$, an extended lumped conductance model was developed. The node definition was performed dividing complex geometries into smaller parts, whence the nodes characteristics were calculated: mass, connecting areas, and distances between centers. These, along with the thermal properties of the material, allowed calculating the thermal resistor network. The following discretization, with a total amount of 105 metallic nodes, was used:

- The liner was divided into five axial, two radial, and six circumferential levels, so that the cylinder liner was represented by 60 nodes.

- The piston was divided into ten nodes as shown in Fig. 4 (symmetric behaviour was assumed). Nodes named $\mathrm{P} 1, \mathrm{P} 7$ and $\mathrm{P} 9$ are in contact with in-cylinder gases, node P3 contains the piston rings, a conductive conductance between piston and liner, and also the oil gallery.

- $\quad$ The cylinder head model was divided into 35 nodes (see Fig. 5): 14 nodes in contact with in-cylinder gases including the 4 valves and the injector tip; 10 nodes just above the previous ones, 2 for the ports, 2 at the valves stems and 1 for the rest of the injector, and 2 for the rest of the cylinder head material, separated into intake and exhaust sides.

The boundary conditions were represented by six convective nodes (in-cylinder gases, air at the intake ports, gases at the exhaust ports, coolant at liner, coolant at the cylinder head, and lubricating oil), characterized by their average temperatures and film coefficients [33]. 
Once the thermal model is defined, the energy balance in each node is performed, considering the corresponding conductive, convective and radiative HT flows. Arranging the set of equations into a matrix, the following expression is obtained:

$$
\begin{aligned}
& {\left[\begin{array}{ccccc}
I_{\text {conv }} & 0 & 0 & 0 & 0 \\
0 & I_{g a s-c y l} & 0 & 0 & 0 \\
K_{c o n v-c y l} & K_{g a s-c y l} & K_{c y l-c y l} & K_{c y l-p i s} & 0 \\
K_{c o n v-p i s} & 0 & K_{p i s-c y l} & K_{\text {pis-pis }} & 0 \\
K_{\text {conv-CH }} & 0 & 0 & 0 & K_{C H-C H}
\end{array}\right]} \\
& {\left[\begin{array}{c}
T_{\text {conv }} \\
T_{g a s-c y l} \\
T_{c y l}^{*} \\
T_{p i s} \\
T_{C H}
\end{array}\right]=\left[\begin{array}{c}
T_{c o n v}^{*} \\
T_{g a s-c y l}^{*} \\
\dot{Q}_{c y l} \\
\dot{Q}_{p i s} \\
\dot{Q}_{C H}
\end{array}\right]}
\end{aligned}
$$

where: $I_{\text {conv }}$ and $I_{g a s-c y l}$ are identity matrices corresponding to the boundary conditions in convective nodes. $K_{\text {conv-cyl }}$, $K_{c o n v-p i s}$ and $K_{c o n v-C H}$ represent the convective conductances at liner, piston and cylinder head respectively. $K_{\text {gas }}$ cyl represents the convective conductance sub-matrix accounting for the connection between in-cylinder gas and liner nodes with variable heat exchange area. $K_{c y l-c y l}, K_{p i s-p i s}$ and $K_{C H-C H}$ are the conductive matrices between the liner, piston and cylinder head nodes. $K_{p i s-c y l}$ and $K_{c y l-p i s}$ are the conductive matrix between piston and liner nodes (in contact due to the rings).

$T_{\text {conv }}^{*}$ is the boundary conditions temperature vector $\left(T_{\text {oil }}, T_{\text {cool }}\right.$, mean gas temperature in the chamber...) which is known by measurement or calculation, $T_{g a s-c y l}^{*}$ is a vector including the apparent gas temperatures seen by liner nodes (it is calculated taking into account that liner nodes are in contact with chamber gases only during part of the cycle). $T_{c y l}, T_{p i s}$ and $T_{C H}$ are the temperature vectors to determine, corresponding to liner, piston and cylinder head nodes respectively. Finally, $\dot{Q}_{c y l}, \dot{Q}_{p i s}$ and $\dot{Q}_{C H}$ are the radiation heat fluxes to liner, piston and cylinder head nodes.

Most the required information to complete the analysis is obtained from the convective and radiative models described, and from the nodes geometry and thermal properties. However, there is an important uncertainty in the HT coefficient in the liquid convective nodes: coolant and oil in contact with liner, cylinder head and piston and ring-liner contact. They were obtained as described in the Submodel adjustment section.

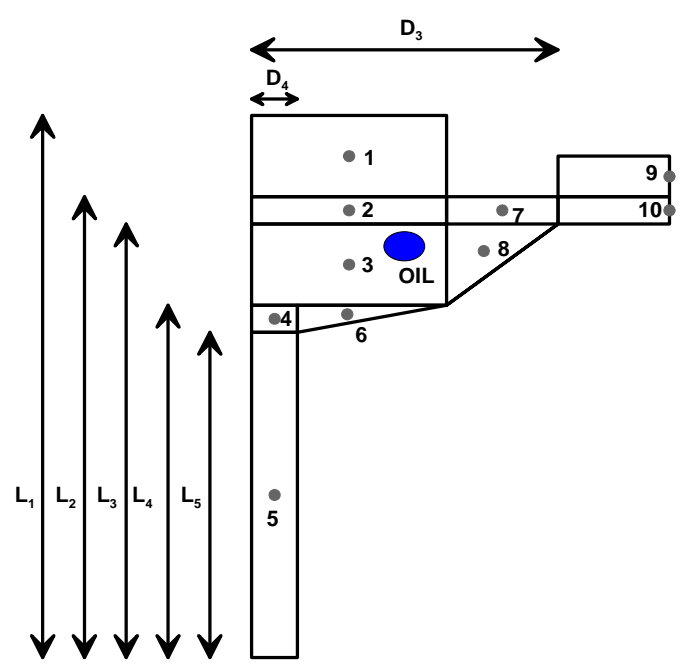

Figure 4. Schema of the conductace lumped model of the piston.

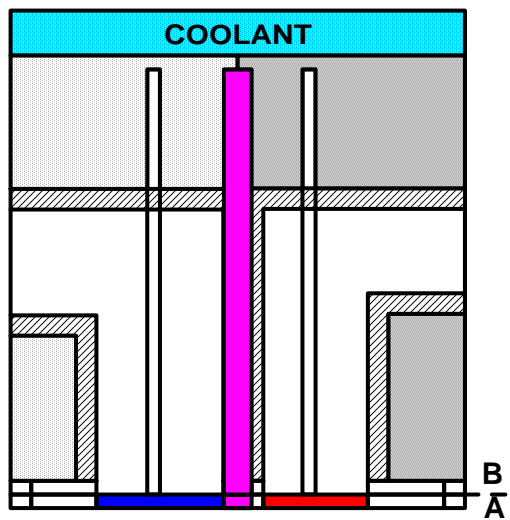

IET EIT

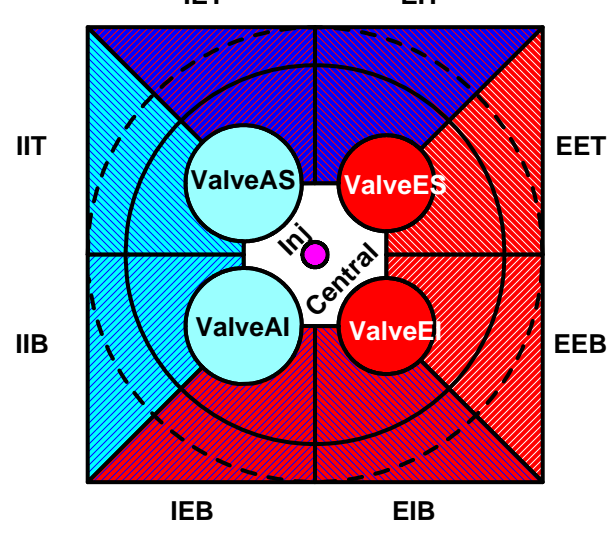

Figure 5. Schema of the conductace lumped model of the cylinder head.

\section{Mechanical losses models}

Six submodels were used to calculate each term of the mechanical losses, as described in the following subsections. 


\section{Piston assembly friction}

According to the literature $[23,48,49]$, the friction in the piston use to be split in two parts: friction in the rings and friction in the skirt, being the first term the most important. In both cases, the friction force is obtained as

$F_{f r}=f F_{N}(10)$

where $F_{f r}$ is the friction force, $f$ is the friction coefficient, and $F_{N}$ is the normal force.

In the case of the rings, $F_{N}$ is obtained considering both the normal force resulting from the elastic tension of the rings due to the mounting and the pressure of the gases in the combustion chamber. To estimate the pressure behind each ring a simple blow-by model was proposed. The model considers one volume between the first and second rings and another between the second and the oil ring. Volumes were assumed to be connected by isentropic nozzles. An empirical adjustment of the nozzle size between volumes is performed at each operating conditions so that the blow-by modeled coincides with the experimental value.

The friction coefficient is obtained from the Stribeck diagram, in which the mixed region is assumed to be linear and in the hydrodynamic regions $f$ depends on the square of the duty parameter [23]. The Stribeck diagram is completely defined assuming a dry friction coefficient $f_{0}=0.14$ [48], critical friction coefficient $f_{c r}=0.0225$ at a critical value of the duty parameter $S_{c r}=0.0001$ [23]. As the values of these parameter can vary depending on the materials and surface conditions a global empirical adjustment will be later described.

With respect to the friction in the skirt, the normal force was obtained from the calculation of the instantaneous force between piston and liner, considering both the forces due to the gas pressure in the chamber and the reciprocating inertial masses. Regarding the friction coefficient in the piston skirt, a similar model as in the piston ring is considered. In this case, the lubrication is assumed to be always hydrodynamic.

The final expression for the friction in the piston ring assembly can be expressed as:

$F_{\text {fr,piston }}=K_{\text {piston }}\left(\sum_{i} f_{i} F_{N, i}+f_{s} F_{N, s}\right)$

where $K_{\text {piston }}$ is an empirical constant that account for the uncertainties derived from the use of the stated constants obtained from literature, $f_{i}$ and $f_{s}$ are the friction coefficient in the ring and in the skirt, and $F_{N, i}$ and $F_{N, s}$ are the normal forces in the ring and the piston skirt.

\section{Crankshaft bearing friction}

Bearings friction use to contribute in a lower extent than the piston to the total friction, being usually assumed that they work under hydrodynamic lubrication. For the calculation of the friction forces in the crankshaft, if was assumed two components [50]: the first term in expression (13) represents the shearing force of the oil film (unloaded bearing term), and

Page 7 of 17 the second the effect of the pressure component (loaded bearing term):

$F_{f r, \text { bear }}=K_{\text {bear }}\left[\frac{\pi^{2} D_{\text {bear }}{ }^{2} \cdot L_{\text {bear }} \mu n}{c \sqrt{1-\varepsilon^{2}}}+\frac{c F_{N, \text { bear }} \varepsilon}{D_{\text {bear }}} \cdot \operatorname{sen}(\varphi)\right](13)$

where $D_{\text {bear }}$ and $L_{\text {bear }}$ are the bearing diameter and length, $\mu$ is the oil viscosity, $n$ is the engine speed, $c$ is the radial clearance, $\varepsilon$ de eccentricity ratio of the bearing, $F_{N, \text { bear }}$ is the normal force in the bearing, and $\varphi$ is the attitude angle. The values of the constants are $c=0.0025 D$ (where $D$ is the bore), $\varepsilon=0.0007$ and $\varphi=\tan ^{-1}\left(\frac{\pi \sqrt{1-\varepsilon^{2}}}{4 \varepsilon}\right)$ [23]. It was checked that the relative weight of the terms in (13) can vary slightly if the constants vary in the expected range, however the global trend do not vary importantly. Similarly to the piston, one empirical constant $K_{\text {bear }}$ was included for accounting the differences with respect to the constants values assumed by default. The normal force in the connecting rod can easily be computed from the dynamic analysis, while additional hypothesis was made for the main bearing, where only the effect of the adjacent cylinders was assumed. In both cases, the effect of gas pressure and reciprocating inertial masses was considered.

\section{Valves train friction}

The friction in the valve train use to be the least important of all the friction terms. Different elements are involved in the friction of this system, however, it is usually assumed that the most important of them is the friction between the cam and the follower [51], being about $85-90 \%$ of the total friction in the valve train. Hence, only this component was modeled.

Due to the important forces in the contact, boundary and elasto-hydrodynamic lubrication is usually assumed [23,52]. The key issue is the determination of the oil thickness in the contact, for which several proposals with the following shape can be found in the literature:

$H=\frac{h_{\text {oil }}}{R_{\text {cam }}}=k_{1} U^{k 2} G^{k 3} W^{k 4}(14)$

where $H$ is the non-dimensional oil thickness, $h_{\text {oil }}$ is the oil thickness, $R_{\text {cam }}$ is the cam radius that cam be computed from the radius of the base circle of the cam and valve lift, $U, G$, and $W$ are three non-dimensional parameters depending on oil viscosity, cam geometry and normal force, which detailed expressions can be seen in [23], and $k_{1}, k_{2}, k_{3}$ and $k_{4}$ are constants which value vary between different authors. The reference values assumed [23] were: $k_{1}=2.65, k_{2}=0.7$, $k_{3}=0.54$ and $k_{4}=-0.13$. A global fitting constant, $K_{\text {valv }}$, was also included in the. Thus, the friction force in the cam-follower contact is:

$F_{f r, v a l v}=K_{\text {valv }} F_{f r, v a l v}^{0}(15)$

where $F_{f r, v a l v}$ is the friction force in the cam-follower contact and $F_{f r, v a l v}^{0}$ is the friction force calculated with the reference model. 


\section{Ancillaries systems losses}

Three subsystems were considered: fuel injection, cooling and lubrication. All of them use pumps that are driven by the crankshaft to provide the corresponding mass flows.

Engine 1 has a common rail system in which the fuel pump includes both a pressure control valve (PCV) and a volume control valve (VCV), hence its behavior is different from conventional piston pumps. In conventional piston pumps the total amount of fuel compressed in the piston (part of which is injected and part returns to the low pressure circuit) basically depends on the pump rotating speed and pump size. However, some characterization tests of the pump unit used showed that the total fuel mass flow variation at different engine speeds is limited and there can be also some effect with the load, due to the strategy of the ECU that controls the VCV. Thus a characterization campaign was carried out in the experimental setup. The experimental measurement (see Table 3) consisted in a speed, rail pressure and injected mass swepts in motoring conditions (the injector were removed from the combustion chamber). For each engine speed, the rest of friction losses were kept constant by controlling the oil temperature. Thus the mechanical losses variations could be attributed to injection setting changes.

Table 3.Experimental test.

\begin{tabular}{|c|c|c|}
\hline \multirow{3}{*}{$\begin{array}{c}\text { Fuel pump } \\
\text { characterization }\end{array}$} & $n$ & $1000,2000,3000,4000$ \\
\hline & $p_{\text {rail }}$ & $200,400,800,1200,1600$ \\
\hline & Fuel mass & Equivalent to $0-50 \%$ load \\
\hline$C_{W 1}$ adjustment & $n$ & $1000-4000$ (500 rpm steps) \\
\hline \multirow{4}{*}{$\begin{array}{l}\text { Lumped model } \\
\text { adjustment }\end{array}$} & $n$ & $1500-3500$ (500 rpm steps) \\
\hline & Load & $25-75 \%$ \\
\hline & $T_{\text {cool }}$ & $47-97^{\circ} \mathrm{C}$ \\
\hline & $T_{\text {oil }}$ & $75-115^{\circ} \mathrm{C}$ \\
\hline \multirow{3}{*}{$\begin{array}{l}\text { Friction model } \\
\text { adjustment } \\
\text { (28 operating } \\
\text { points) }\end{array}$} & $n$ & $1000-4000$ (500 rpm steps) \\
\hline & Load & $25 \%, 50 \%, 75 \%, 100 \%$ \\
\hline & $\begin{array}{c}T_{\text {oil }} \text { (depending } \\
\text { on operating } \\
\text { conditions) }\end{array}$ & $80^{\circ} \mathrm{C}-125^{\circ} \mathrm{C}$ \\
\hline \multirow{2}{*}{$\begin{array}{c}\text { Validation } \\
\text { (52 operating } \\
\text { points) }\end{array}$} & $n$ & $1000-4000$ \\
\hline & Load & $10 \%-100 \%$ \\
\hline
\end{tabular}

The following expression for the fuel pump power was assumed

$N_{\text {fuel }}=\frac{Q_{\text {fuel }} p_{\text {fuel }}}{\eta_{\text {fuel }}}(16)$

where $p_{\text {fuel }}$ is the rail pressure and $\eta_{\text {fuel }}$ use to range between $0.85-0.9$ [23]. Then, using the measured mechanical losses in (16), the following empirical correlation for the total volumetric flow was derived:

$Q_{\text {fuel }}=k_{\text {fuel }} * m_{\text {fuel }}^{0.6}(17)$

Page 8 of 17 where $k_{\text {fuel }}=3.43 \cdot 10^{-9} \frac{\mathrm{m}^{3} / \mathrm{s}}{\left(\frac{\mathrm{g}}{\mathrm{s}}\right)^{\mathbf{0 . 6}}}$ and $m_{\text {fuel }}$ is the injected fuel mass. In combustion operation, the power to drive the injection pump was directly obtained from the combination of expressions (16) and (17).

A simplification of the complete cooling system of the engine consists in the coolant pump and restricted passages through the engine and radiator. The coolant pump is a centrifugal pump which rate flow depends on its speed, efficiency and the pressure provided. The pressure required to circulate the coolant through the system can be estimated as

$p_{\text {cool }}=k 1_{\text {cool }} Q_{\text {cool }}^{2}$

where the constant $\boldsymbol{k} \mathbf{1}_{\text {cool }}=\mathbf{5 . 1 4} \cdot \mathbf{1 0}^{-\mathbf{5}} \frac{\boldsymbol{b a r}}{\left(\frac{l}{\min }\right)^{2}}$ was adjusted for Engine 1.

As the coolant pump is not volumetric, its mass flow is not necessary linear with the engine speed. However, experimental results available showed that this hypothesis is quite accurate, thus the following expression was used:

$$
\boldsymbol{Q}_{\text {cool }}=\boldsymbol{k} \boldsymbol{2}_{\text {cool }} \boldsymbol{n}(19)
$$

where $k 2_{\text {cool }}=5.51 \cdot 10^{-2} \frac{\left(\frac{l}{\mathrm{~min}}\right)}{\mathrm{rpm}}$ and $n$ is the engine speed. Finally, the pump power was calculated as follows:

$N_{\text {cool }}=\frac{Q_{\text {cool }} p_{\text {cool }}}{\eta_{\text {cool }}}(20)$

where a value for the efficiency about 0.85 was assumed.

The last system to model is the oil pump, which power can be estimated as:

$N_{\text {cool }}=\frac{Q_{\text {oil }} p_{\text {oil }}}{\eta_{\text {oil }}}(21)$

where the oil pressure $p_{\text {oil }}$ was measured and a pump efficiency $\eta_{\text {oil }}=0.9$ is assumed. As the oil pump is a volumetric pump, its volumetric flow is directly related with engine speed:

$$
\boldsymbol{Q}_{\text {oil }}=\boldsymbol{k}_{\text {oil }} \boldsymbol{n}(22)
$$

where a $k_{\text {oil }}=0.0079 \frac{\left(\frac{l}{\min }\right)}{r p m}$ was estimated from available manufacturer data.

\section{Submodels adjustment}

At this point all the proposed submodels have been presented and only some adjusting process must be done. The adjustment includes the convective heat transfer constant $C_{W 1}$, the nodal model adjustment and $K_{\text {piston }}, K_{\text {bear }}, K_{\text {valv }}$.

The $C_{W 1}$ value is a key issue for the GEB, as it scales the incylinder convective HT. The adjustment process is based on the characterization of the effect of different engine 
uncertainties (real compression ratio, TDC position, pressure pegging, engine deformations and $C_{W 1}$ ) on the thermodynamic cycle during motoring conditions [53]. A detailed description of the process can be found in [54], in short, the method search for the best combination of the uncertainties that minimizes simultaneously the error of the heat release during motoring conditions (when no combustion takes place and the rate of heat release should be identically null) and the compressionexpansion pressure evolution. The experimental conditions used are indicated in Table 3. As result of the adjustment, a value of $C_{W 1}=2.3$ was obtained.

The next model to adjust was the lumped nodal model. Using metal temperature measurements in Engine 2, the convective heat transfer coefficients between cylinder-coolant, cylinder head-coolant, oil-piston and oil-liner were adjusted minimizing the differences between modeled results and measurements. The adjustment was performed by changing the constant correlation of the type $N u=k R e^{0.8}$, covering a wide range of engine operating conditions as detailed in Table 3. Fig. 6 shows some example of the comparison of the modeled and measured result in some representative positions: one node in the hottest part of the engine (the piston rim) and one in the coolest part (liner) . In both cases the model is able to predict accurately the trends at different operating conditions, being the maximum error in the liner lower to $4^{\circ} \mathrm{C}$ and $15^{\circ} \mathrm{C}$ in the piston. Taking into account the wide range of operating conditions included, these results were considered satisfactory.

The adjustment of the constants $K_{\text {piston }}, K_{\text {bear }}, K_{\text {valv }}$ of the friction losses models was carried out using a test matrix of 28 operating condition ranging from low to high engine speeds and loads, as detailed in Table 3. The experimental mechanical losses were computed from the difference between net indicated power, obtained from in-cylinder pressure, and brake power, so that:

$$
\begin{aligned}
N_{i}-N_{p}-N_{b}= & N_{f r, p i s t o n}+N_{f r, \text { bear }}+N_{f r, \text { valv }}+ \\
& +N_{f u e l}+N_{\text {cool }}+N_{\text {oil }}
\end{aligned}
$$

where $N_{f r, p i s t o n}, N_{f r, b e a r}, N_{f r, v a l v}$ are the power of the friction losses in the piston assembly, bearings and valves train, which depends on $K_{\text {piston }}, K_{\text {bear }}, K_{\text {valv }}$. A least squared adjustment was applied to minimize the error of the predicted vs measured mechanical losses. In a first adjustment the values obtained were $K_{\text {piston }}=0.6, K_{\text {bear }}=3.9$, and $K_{\text {valv }} \simeq 2.5$.

It seems clear that the accurate estimation of friction components depends on the derivation of suitable values for the empirical coefficients. The discrepancy of the constants with respect to the reference values $\left(K_{\text {piston }}=K_{\text {bear }}=K_{\text {valv }}=\right.$ 1 ) is a consequence of the different engine characteristics. Moreover, uncertainties regarding the Stribeck diagram, ring forces or bearing geometry and tolerances can also be affecting the results. This discrepancy with respect to reference values is also reported by other authors such as Kouremenos et al. [55], which proposed "variable" constants values as a function of the engine speed. As it was found that friction losses were overestimated at low engine speed, this approach was also considered. Another justification for the necessity to consider different constants at different engine speed can be found in the fact that in the reference model only very limited speed variation was considered [23]. A linear correlation for the piston constant was finally proposed,

$K_{\text {piston }}=k 1_{\text {piston }}+k 2_{\text {piston }} n$. In the case of $K_{\text {bear }}$ and $K_{\text {valv }}$ no clear improvement was found and they were maintained constant for all operating conditions. The final fitting constant are $K_{\text {piston }}=k 1_{\text {piston }}+k 2_{\text {piston }} n$ (ranging from 0.42 at $1000 \mathrm{rpm}$ to 0.73 at $4000 \mathrm{rpm}) K_{\text {bear }}=3.9$, and $K_{\text {valv }}=2.5$. Top part of Fig. 7 shows the experimental vs modeled mean effective pressure due to friction and ancillaries (pumping has been omitted as it is directly measured from in-cylinder pressure) using a constant value for $K_{\text {piston }}$ or the linear variation. As seen in the bottom part, the absolute mean error diminishes from about 200 mbar to 100 mbar, while the stated effect of engine speed on the error is compensated.
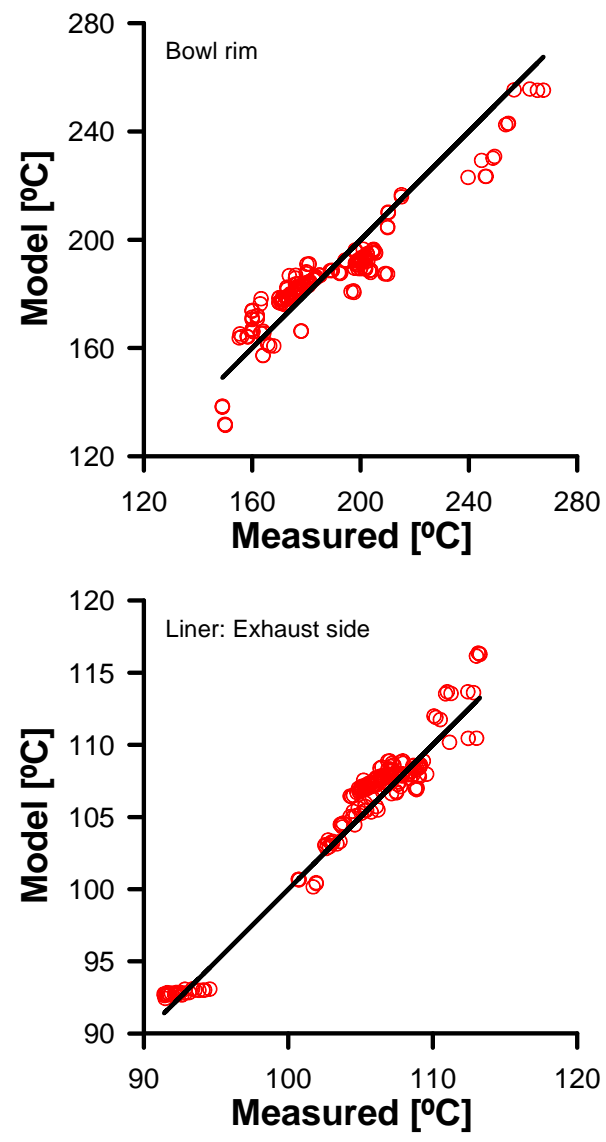

Figure 6. Modeled and experimental wall temperatures in the bowl rim and exhaust side of the liner 

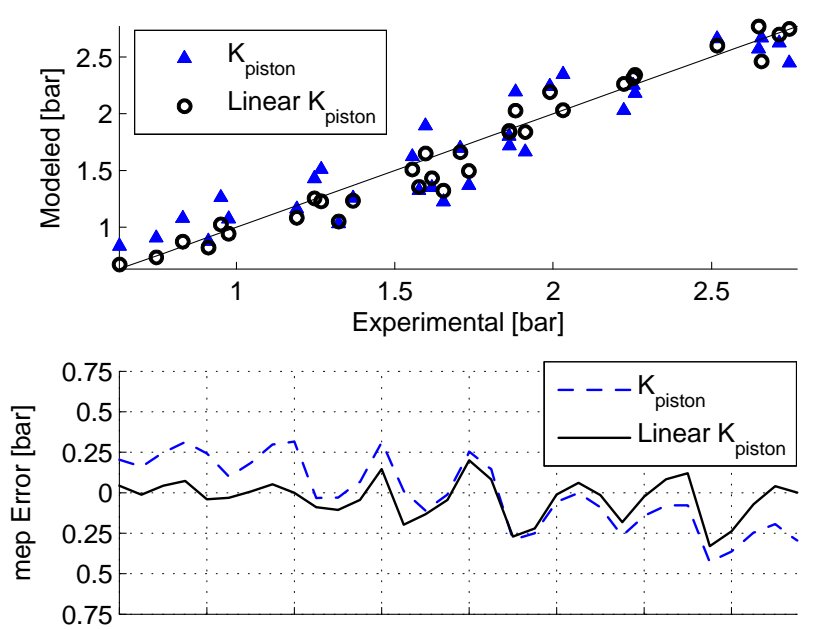

Figure 7. Modeled and experimental mean effective pressure due to friction and ancillaries losses.

\section{Validation}

Once all the individual submodels were adjusted, the analysis tool CALMEC was ready to be used in GEB analysis. The first step was validating the results of the internal models with the external measurements. A first validation was performed through the comparison between the total amount of modeled $\mathrm{HT}, \dot{Q}_{\text {tot,mod }}$, and the external measurements, $\dot{Q}_{\text {tot,exp }}$ :

$$
\begin{gathered}
\dot{Q}_{\text {tot }, \text { mod }}= \\
=\left[\dot{Q}_{c h a m, \text { cool }}+\dot{Q}_{\text {cham }, \text { oil }}+\dot{Q}_{\text {ports }}+N_{a}+N_{\text {fr }}\right]_{\text {mod }} \approx \\
\approx\left[\dot{Q}_{\text {cool }}+\dot{Q}_{\text {oil }}-\dot{Q}_{E G R}+\dot{Q}_{\text {misc }}\right]_{\text {exp }}=\dot{Q}_{\text {tot } \text { exp }}
\end{gathered}
$$

Internal terms consist of $\dot{Q}_{c h a m, c o o l}+\dot{Q}_{\text {cham,oil }}$ that is the total amount of heat transfer from the chamber to the walls, obtained with the described HT models and which repartition between coolant and oil is made thanks to the lumped conductance model, $\dot{Q}_{\text {ports }}$ is modeled with the HT model to the ports and the power losses due to friction and ancillaries is assumed to be finally degraded to $\mathrm{HT}$ to coolant and oil. From the experimental measurements, $\dot{Q}_{c o o l}, \dot{Q}_{o i l}$ and $\dot{Q}_{E G R}$ are directly computed from fluid mass flows and temperature drops. Although $\dot{Q}_{E G R}$ is part of the internal analysis, it was subtracted in the experimental term. Finally, a miscellanea term has been included, $\dot{Q}_{m i s c}$, which is mainly formed by the $\mathrm{HT}$ to the ambient, $\dot{Q}_{\text {ext }}$, but also includes some minor terms such as blow-by leakage, unburned products and the sensible enthalpy of the fuel returning to the tank. $\dot{Q}_{m i s c}$ is calculated as the residual of the rest of experimental energy flows measured in the external analysis, i.e. the experimental unbalance. Fig. 8 shows the two terms of expression (22), that is, the total heat transfer modeled in the internal GEB, $\dot{Q}_{t o t, m o d}$, vs total experimental HT measured, $\dot{Q}_{t o t, \text { exp }}$, . The experimental operating conditions cover the complete engine map as detailed in Table 3. As can be seen, the model follows the global trend with no clear deviation from the measurement in all the power range, from low power (operating points at low speed and load) up to high power (high speed and load). Regarding the dispersion of the prediction, the mean error found is about $8 \%$, which in terms of the fuel energy at each operating condition is about $3 \%$.

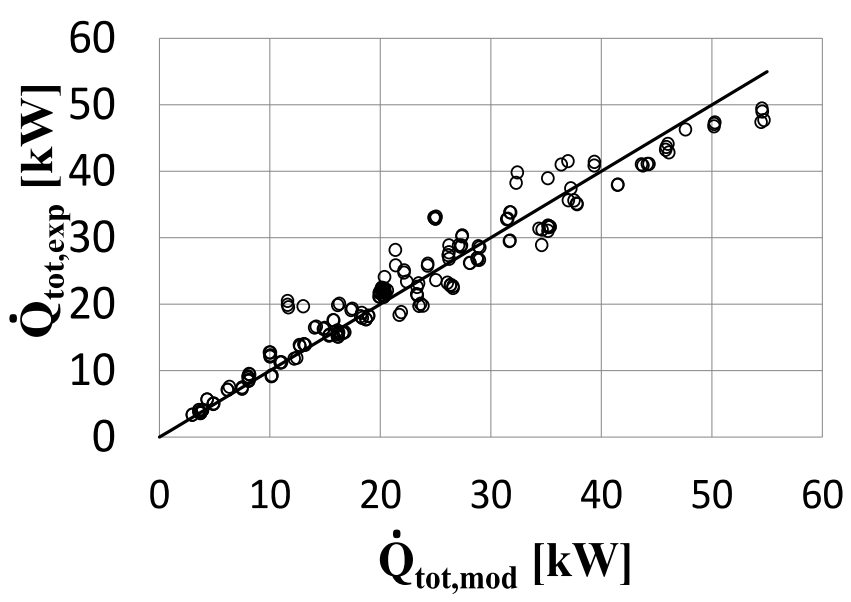

Figure 8. Total internal (modeled) vs external (experimental) heat transfer terms

Concerning the repartition of HT to the coolant and oil, Fig. 9 and 10 show their respective modeled and measured comparison.

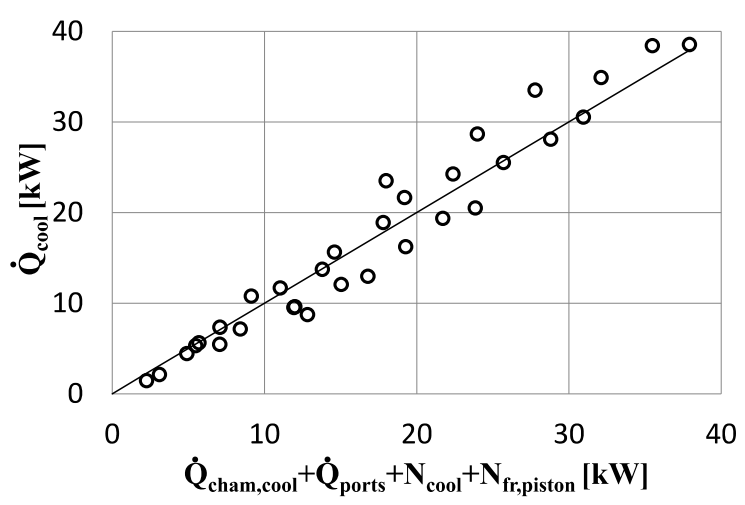

Figure 9. Modeled and measured total heat transfer to the coolant

In the case of the coolant, the modeled HT includes the HT from the chamber to the coolant, the HT in the ports, the power to drive the coolant pump, which is dissipated as fluid friction within the fluid, and the friction losses in the piston assembly. Although in the last case some of the friction can reach the oil that is cooling the piston, it was assumed that most of it was released to the coolant. This can be justified considering that most of the piston assembly friction take place in the compression piston rings, where the friction heats the liner and the rings. However, the thermal resistance is much lower in the path towards the coolant than the oil, and hence, the liner temperature is much cooler than that of the piston node in contact with the ring $\left(90-150^{\circ} \mathrm{C}\right.$ vs $\left.110-300^{\circ} \mathrm{C}\right)$, thus increasing the HT to the liner. As seen in Fig. 9, the modeled values 
follow well the experimental trend, although the dispersion is a bit higher than in the case of $\dot{Q}_{t o t, m o d}$. In the sake of rigor two additional terms should also be included: the HT to the ambient and the internal heat transfer from oil to coolant. However, neither of them can be accurately estimated. In the case of the HT to the ambient, $\dot{Q}_{\text {ext }}$ is available, however it includes part of HT coming from coolant but also from oil, convection and radiation in the turbo. Regarding the $\mathrm{HT}$ from oil to coolant in the engine block, a raw estimation can be performed computing the difference between the external value, $\dot{Q}_{\text {oil }}$, and all the modeled internal terms heating the oil $\left(\dot{Q}_{\text {cham }, \text { oil }}+\right.$ $\left.N_{f r, b e a r}+N_{f r, c a m}+N_{\text {oil }}\right)$; however the accuracy of this estimation is limited as it accounts for the HT from oil to the coolant but also some HT going from oil to the ambient. In any case, it was checked that $\dot{Q}_{\text {ext }}$ and the raw estimation of the HT from oil to coolant are similar, and much lower than the total HT to the coolant; hence they compensate each other and the difference between them would affect in a low extent to the results presented in Fig.9.

The experimental and modeled HT to the oil, $\dot{Q}_{o i l}$ and $\dot{Q}_{c h a m, o i l}$ are plotted in Fig. 10, where it can be seen that the higher the power is the higher the difference between modeled and experimental values are. Taking into account the previous comments, this behavior can be justified considering the HT from the oil to the coolant throughout the metal wall and the HT from oil to the ambient. In both cases, HT increases with the oil-coolant and oil-ambient temperature differences, which increases at higher engine power (and thus at higher $\dot{Q}_{o i l}$ ).

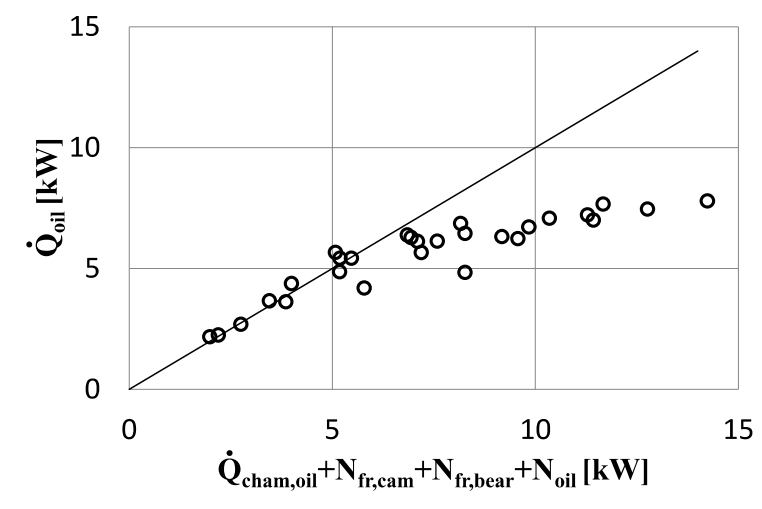

Figure 10. Modeled and measured heat transfer to the oil

\section{Engine map analysis}

Once the thermal balance was validated, this section shows an example of analysis for the complete engine map. In the sake of brevity, only some partial results will be shown. Figs. 11 to 18 show some examples of relevant terms of the external and internal GEB in Engine 1.

Fig. 11 shows the net indicated efficiency (deducting the pumping power) in the complete map. It can be highlighted that its variation range in the complete map is not very important (between 36-43\%), much lower to the brake efficiency shown in Fig. 12 (28-39\%). The reason for the stable behavior of the indicated net efficiency is the combination of different effects: on the one hand combustion process is more adiabatic at higher engines speed and load, however the pumping process shows almost the opposite trend: it is smaller at low engine speed and high load, and higher at high engine speed and low load (in relative terms with respect to the fuel energy). Finally, the injection setting tends to reduce the difference in the combustion duration at different operating conditions, by means of a different number of injections and rail pressures.

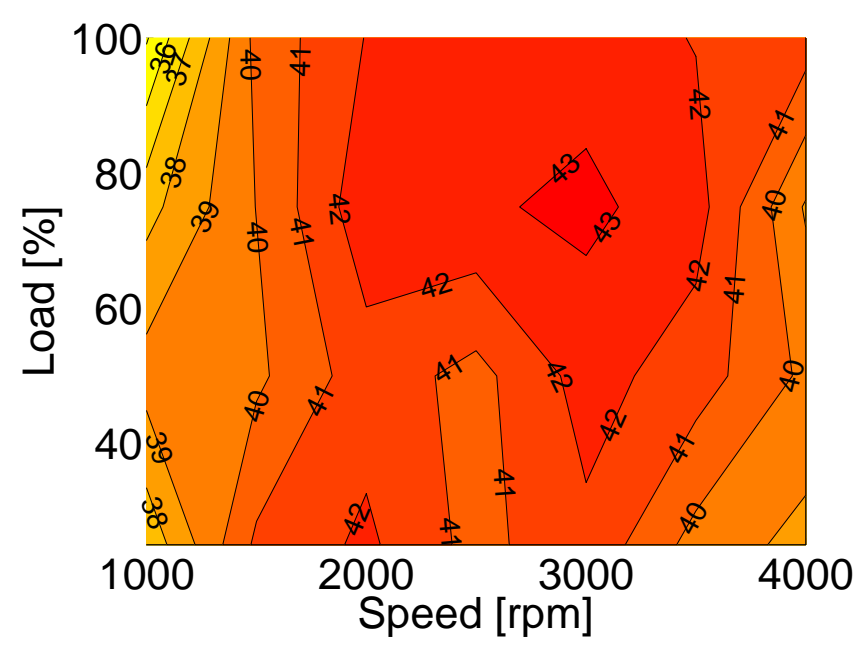

Figure 11. Net indicated efficiency

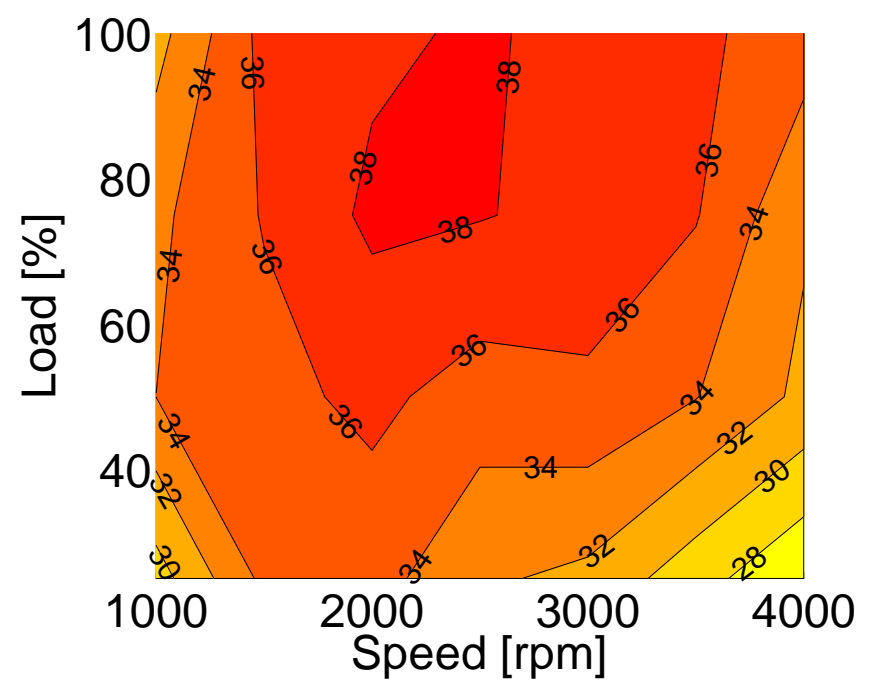

Figure 12. Brake efficiency

The difference of net indicated efficiency with respect to the $100 \%$ of efficiency (corresponding to the total amount of fuel energy), is due to the HT losses in the chamber and the exhaust enthalpy flow in the exhaust valve. Regarding the $\mathrm{HT}$, Fig. 13 and 14 show the modeled HT power to the coolant and oil coming from the chamber walls, respectively. Both of them increase with the engine speed and load; being the heat transfer to the oil, in global terms, a bit lower to half the heat 
transfer to the coolant. Part of the enthalpy of the hot exhaust gases leaving the combustion chamber is transferred to the ports walls. Fig. 15 shows the total thermal power transferred to both intake and exhaust ports. The first of them use to be negative because of the low inlet temperatures; however the last is much more important due to the higher temperature difference between gas and walls (exhaust port HT is about 10 times the intake port HT). As shown, the total amount of HT to the ports is lower to that transferred from the chamber to the oil. The addition of HT to the coolant from chamber and ports are the two main terms in the total HT to the coolant, which experimental values are plotted in Fig. 16. The difference between modeled HT to the coolant (in-cylinder HT plus ports $\mathrm{HT}$ ) and the measured values ranges between less that $1 \mathrm{~kW}$ at low engine speed and load to about $10 \mathrm{~kW}$ at full load and $4000 \mathrm{rpm}$. This difference has been properly justified in the previous section.

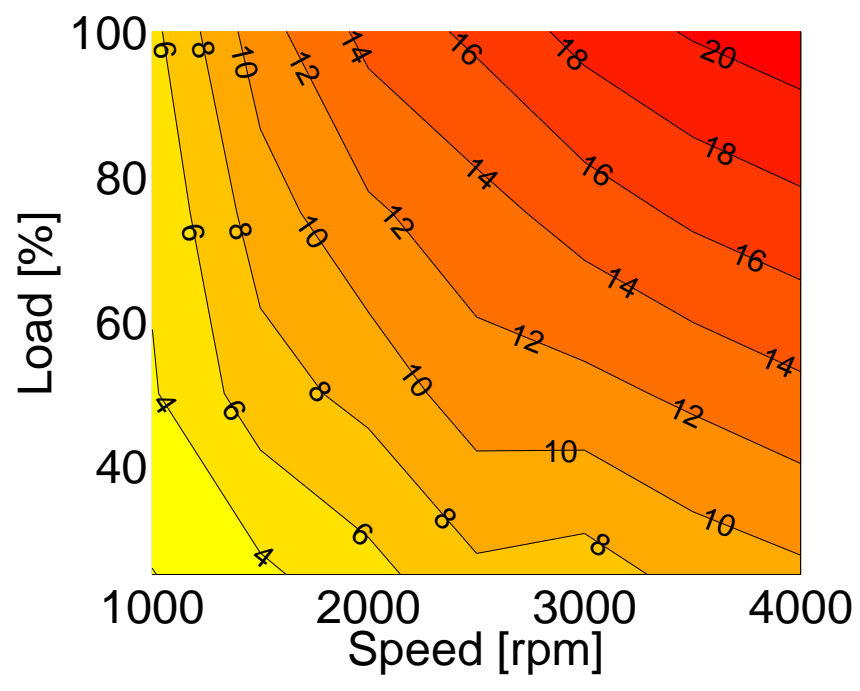

Figure 13. Modeled HT from the chamber to the coolant (in kW)

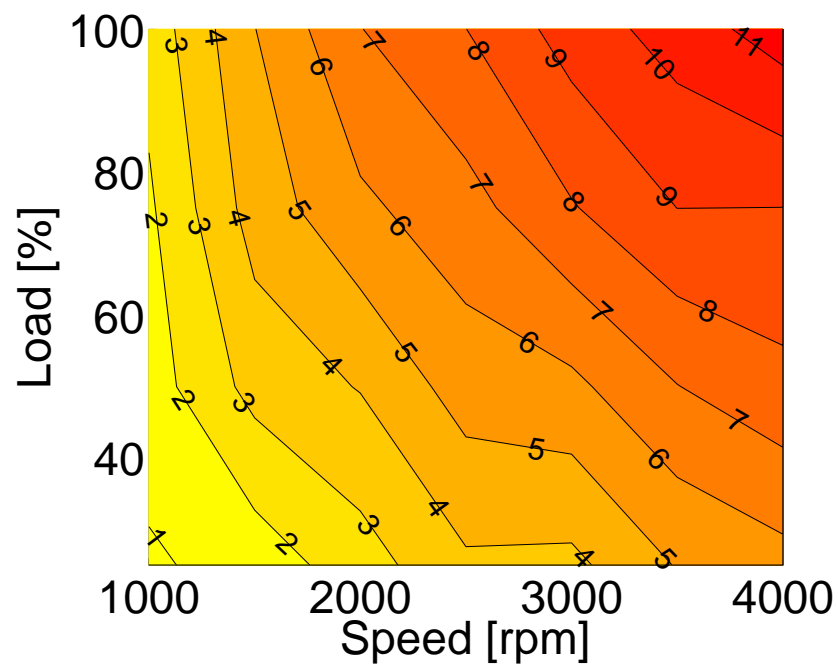

Page 12 of 17
Figure 14. Modeled HT from the chamber to the oil (in kW)

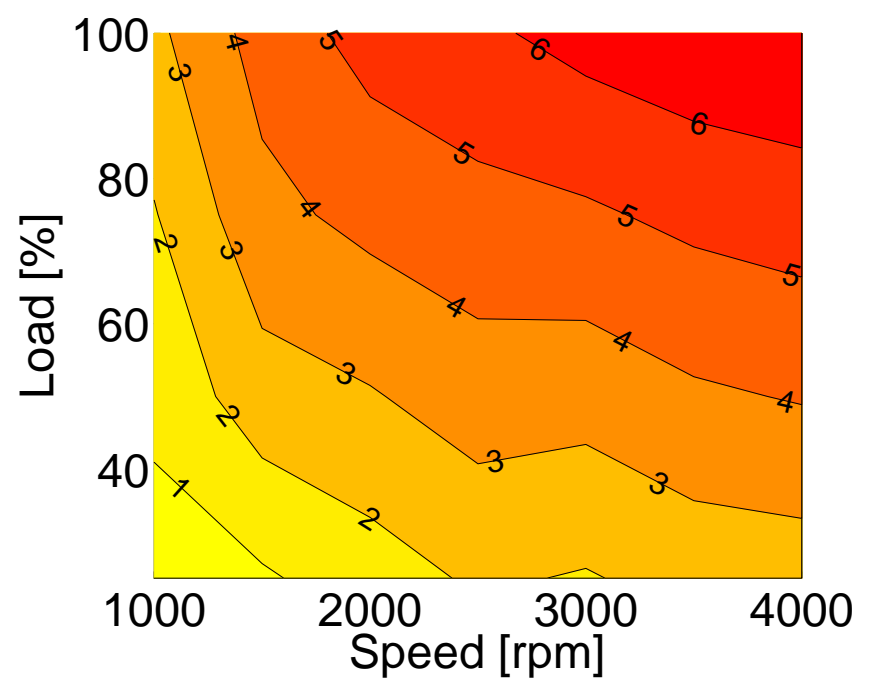

Figure 15. Modeled $\mathrm{HT}$ to the ports (in $\mathrm{kW}$ )

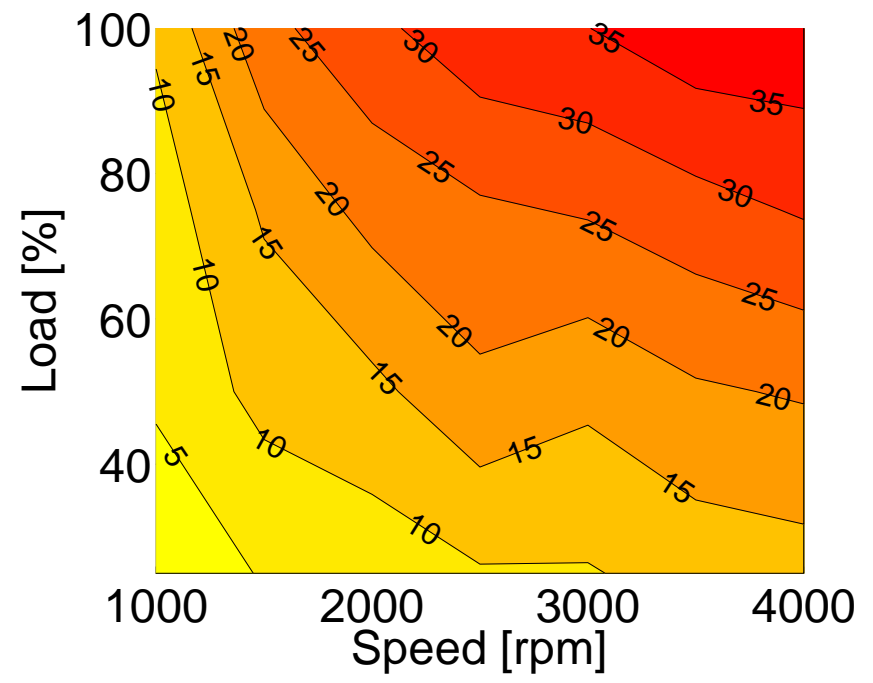

Figure 16. Measured HT to the coolant (in kW)

The difference between the net indicated efficiency plot in Fig. 11 and the brake efficiency in Fig. 12, are due to the friction losses and the power to drive the ancillary systems. Their repartition at three engine speed and the complete range of loads are plotted in Figs. 17 and 18, in absolute and relative terms. In both cases cumulative values of each term are plotted, so that the specific effect of one term can be obtained subtracting the line bellow. Intermediate engine speed showed similar trends. As can be seen the most important term is the piston assembly friction, ranging $40-60 \%$ of the total friction and ancillaries losses, depending on the operating conditions. It is interesting to highlight that this term shows a high sensitivity with the load, while the second most important term, the bearing friction (15-25\% of the total friction and ancillaries losses), is quite stable at different loads. Hence, it can be concluded that piston friction is responsible of most the mechanical losses increment with the load (and the fuel pump in lesser extent). This can be explained taking into account that the elements producing most of the piston friction are the 
compression rings, on which the in-cylinder pressure has a direct influence. Moreover, during the cycle evolution, important friction takes place in the proximity of the TDC where the pressure is high and the instantaneous velocity is low, thus the mixed friction plays an important role in the piston friction. As known, the effect of viscosity is limited in mixed lubrication. On the contrary, bearing has hydrodynamic lubrication, and its unloaded and loaded components, show opposite trend with the load: the term affected by the normal forces in the bearings increases with the in-cylinder pressure, but the term due to the oil shearing force diminishes due to the lower viscosity because of the higher oil temperature. The last friction term, the valve train, shows a limited weight of about $5-10 \%$ of the total friction and ancillaries losses. Regarding the ancillaries, they range about $12-25 \%$ of total friction and ancillary losses, increasing its absolute and relative weight as the engine speed increases. The two most important terms are the power to drive the coolant and the fuel pump, being more important the last of them, except at high engine speed, where they are similar.

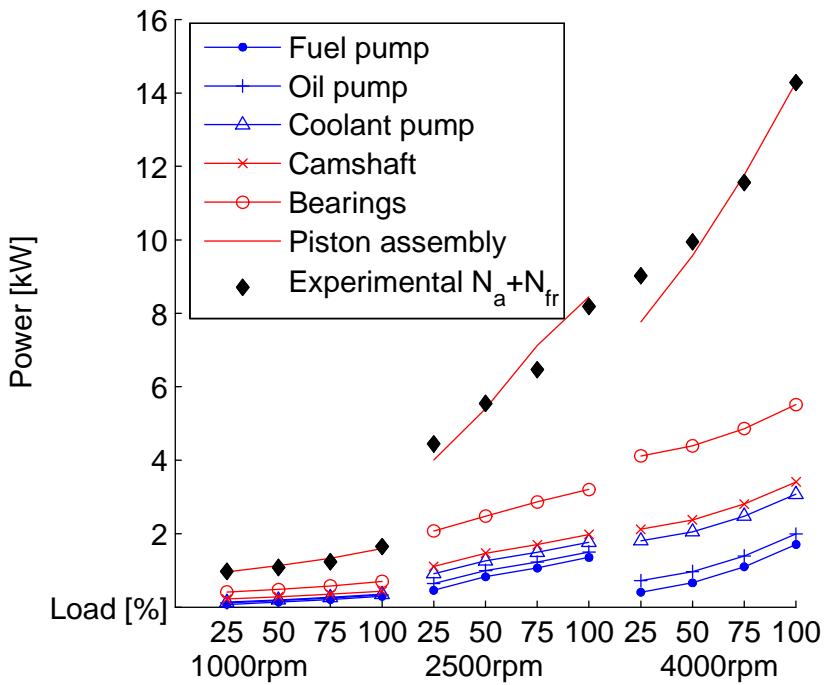

Figure 17. Cumulative friction and ancillaries power losses

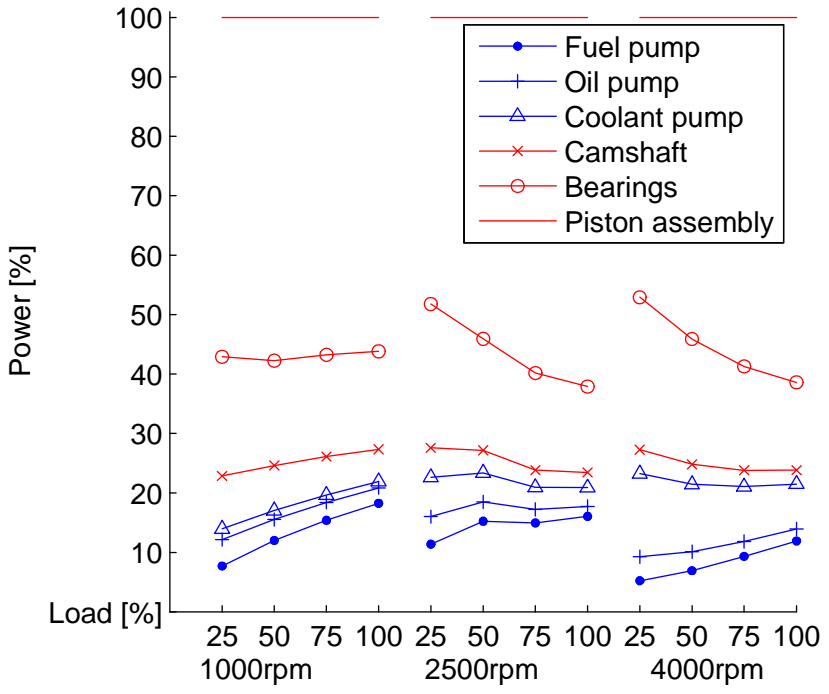

Figure 18. Cumulative percentage of friction and ancillaries losses
Finally, Fig. 19 shows GEB in relative terms for 4 operating points (test identification means speed@load). All the energy terms are referenced with the total fuel energy. For each operating point two columns are plotted: the column at left corresponds to the external GEB based on experimental measurements, while the column at the right includes the internal split of energy. In the external GEB the terms considered are brake power $\left(N_{b},\right), \mathrm{HT}$ to the coolant $\left(\dot{Q}_{c o o l}\right)$ and oil $\left(\dot{Q}_{o i l}\right), \mathrm{HT}$ in the air intercooler $\left(\dot{Q}_{a}\right)$, HT to the turbo oil $\left(\dot{Q}_{\text {turbo }}\right)$, enthalphy flow of the exhaust gases at the turbo exit $\left(H_{\text {exh }}\right)$ and finally, the miscellanea term, $\dot{Q}_{m i s c}$ (formed by $\dot{Q}_{\text {ext }}$ and the rest of minor terms). In the internal GEB the terms are the net indicated power, which in the sake of comprehension has been split into brake power and ancillaries and friction $\left(N_{f r}+N_{a}\right)$, HT from the chamber to the coolant $\left(\dot{Q}_{\text {cham,cool }}\right)$ and oil $\left(\dot{Q}_{\text {cham }, o i l}\right)$, HT to the ports walls ( $\left.\dot{Q}_{\text {ports }}\right)$, HT in the EGR cooler $\left(\dot{Q}_{E G R}\right)$, and finally the enthalpy flow of the exhaust gases at the turbo inlet $\left(H_{\text {int }}\right)$. This last term leads, in the external GEB, to the enthalpy flow of the exhaust gases, the $\mathrm{HT}$ to the turbo and the HT removed in the intercooler.

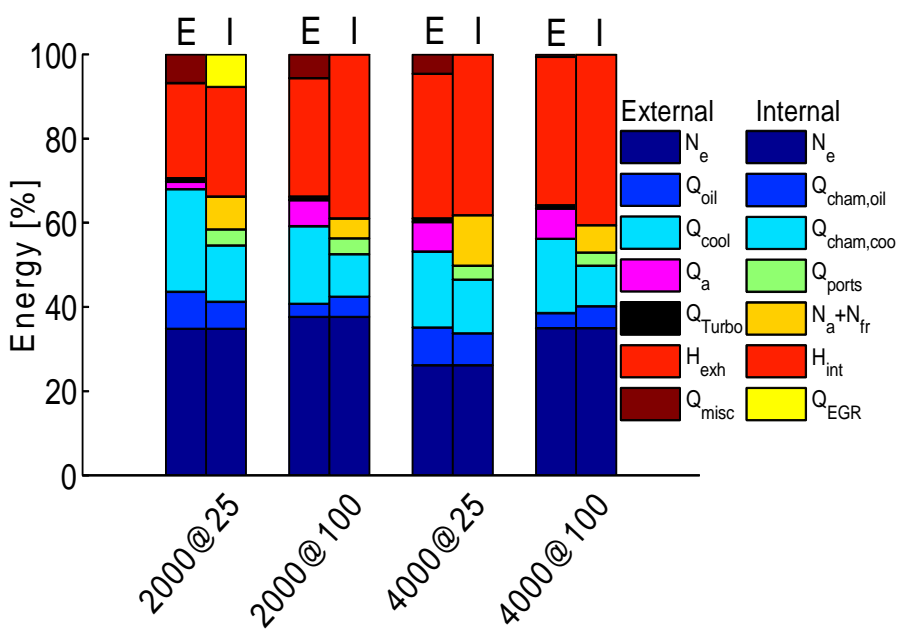

Figure 19. Internal and external GEB at different operating conditions

Brake engine efficiency range between $35-38 \%$ at $2000 \mathrm{rpm}$ and $26-35 \%$ at $4000 \mathrm{rpm}$; the expected increase of efficiency with the load can be observed; in the case of 2000@100, the efficiency is very close to the engine maximum efficiency, about 39\% (see Fig.12).

In global terms, the importance of HT to the coolant tends to diminish with the engine speed (being more evident at low load) and load (being more evident at low speed). Regarding the HT to the oil, the higher the load is, the lower the HT is, being this trend more clearly seen in the experimental measurement than in the modeled HT from the chamber. This trend can be explained by the discussed higher heat transfer from oil to coolant at high load. In relative terms, the HT to the oil shows a low variation with the engine speed.

The only point with EGR is $2000 @ 25$, were this term is about $7 \%$. When comparing this operating point with 2000@100 it can be seen that the energy flow of the EGR, is derived to the exhaust gases, increasing both $H_{\text {exh }}$ and $H_{\text {int }}$. The weight of exhaust gas enthalpy increases with engine speed, but it is 
quite stable with the load (at $2000 \mathrm{rpm}$ the observed increment in mainly produced by the EGR). Considering the discussed $\mathrm{HT}$ and exhaust enthalpy trends, it can be stated that, in general terms, lower HT to the coolant and oil leads to higher exhaust losses.

As can be seen, $\dot{Q}_{\text {misc }}$ has a non negligible weight at low engine speed and load, diminishing as both load or speed increases. This behavior can be explained taking into account that main term in $\dot{Q}_{m i s c}$ is the HT to the ambient which is controlled by the block temperature. As the coolant temperature was maintained about $85^{\circ} \mathrm{C}$ its relative importance diminished when the engine power increases.

Other terms with lower importance are the energy required to cool intake charge, $\dot{Q}_{a}$, higher at higher speed, HT to the ports, which slightly decreases with engine speed and HT to the turbo oil, which is lower to $2 \%$ in all cases.

\section{Summary/Conclusions}

The paper describes a tool called CALMEC, which provides a detailed description of the internal global energy balance of Diesel engines. Having as main input the instantaneous incylinder pressure, the tool is able to detail the energy distribution in the engine, describing the different paths thanks to specific submodels, accounting for all the relevant subsystems. Thus, a combination of physical and semiempirical submodels have been proposed:

- $\quad$ In-cylinder heat transfer models for calculating heat fluxes to the chamber walls due to both convection from gases and radiation from soot.

- Heat transfer model to estimate thermal flux from inlet and exhaust gases to the ports walls.

- $\quad$ Lumped heat transfer model for obtaining the repartition of the heat flux throughout the engine metal elements to the oil and coolant, and estimating the engine wall temperatures.

- Semi-empirical submodels for calculating the friction losses and the power to drive the ancillary systems. Specific proposals for friction in the piston assembly, bearings and valve train, and fuel, coolant and oil pumps have been presented.

The submodel have been adjusted and validated in two versions of a 4-cylinder 1.6 litre DI Diesel engine using experimental measurement of the external thermal flows to different fluids (coolant, block oil, turbo oil...), along with conventional engine measurements.

Good agreement has been found between the global modeled and measured heat transfers, and the heat transfer to the coolant. Some differences between the modeled and experimental heat transfer to the oil were found; they have been justified taking into account the internal heat transfer from oil to coolant throughout the metal parts of the engine.

Regarding the friction losses, it was found that the most important term is the piston friction with a weight of $40-60 \%$ of the total friction and ancillaries losses, being the term with high sensitivity with the load. The second important term is the bearing friction (15-25\% of the total friction and ancillaries Page 14 of 17 losses) while power to drive fuel and coolant pumps are the most important terms of the ancilliaries losses which range about $12-25 \%$ of total friction and ancillary losses.

A simple analysis of the GEB in the engine map, showed that, in general the higher the speed and load are, the lower the HT to the coolant and oil are, while exhaust thermal flow increases. The HT to the ambient, which is negligible at high engine speed and load, is quite important at low speed and load. Global trends of other less important terms have also been highlighted.

The described models are fast and simple enough to be linked with the in-cylinder combustion analysis, thus providing a complete description of the internal engine analysis that, in combination with the external thermal flow measurements, allows assessing the effect of different operating conditions on the global energy repartition.

\section{References}

1. Wang, X., Huang, Z., Zhang, W., Kuti, O.A., Nishida. K.,"Effects of ultra-high injection pressure and micro-hole nozzle on flame structure and soot formation of impinging diesel spray", Appl. Energ. 88(5), 1620-1628, 2011, doi: 10.1016/j.apenergy.2010.11.035.

2. Park, S.H., Yoon, S.H., Lee, C.S. "Effects of multipleinjection strategies on overall spray behavior, combustion, and emissions reduction characteristics of biodiesel fuel", Appl. Energ. 88(1), 88-98, 2011, doi: 10.1016/j.apenergy.2010.07.024 .

3. Al-Hinti, I., Samhouri, M., Al-Ghandoor, A., Sakhrieh, A., "The effect of boost pressure on the performance characteristics of a diesel engine: a neuro-fuzzy approach", Appl. Energ. 86 (1), 113-121, 2009, doi: 10.1016/j.apenergy.2008.04.015.

4. Fontana, G., Galloni, E., "Experimental analysis of a spark-ignition engine using exhaust gas recycle at WOT operation", Appl. Energ. 87 (7) 2187-2193, 2010, doi: 10.1016/j.apenergy.2009.11.022.

5. Fontana, G., Galloni, E., "Variable valve timing for fuel economy improvement in a small spark-ignition engine", Appl. Energ. 86 (1) 96-105, 2009, doi: 10.1016/j.apenergy.2008.04.009.

6. Prasad, B.V.V.S.U., Sharma, C.S., Anand, T.N.C., Ravikrishna, R.V., "High swirl-inducing piston bowls in small diesel engines for emission reduction". Appl. Energ., 88 (7), 2355-2367, 2011, doi:

10.1016/j.apenergy.2010.12.068.

7. Kegl, B., "Influence of biodiesel on engine combustion and emission characteristics", Appl. Energ., 88(5),1803-1812, 2011, doi: 10.1016/j.apenergy.2010.12.007.

8. Guardiola, C., López, J.J., Martín , J., García-Sarmiento, C., "Semiempirical in-cylinder pressure based model for NOX prediction oriented to control applications", Appl. Therm. Eng. 31(16) 3275-3286, 2011, doi: 10.1016/j.applthermaleng.2011.05.048.

9. Heywood, J.B., "Internal combustion engine fundamentals". New York, McGraw-Hill, 1988.

10. Payri, F. et al., "A challenging future for the IC engine: new technologies and the control role", Proceedings of the 2012 IFAC Workshop on Engine and Powertrain Control, Simulation and Modeling (ECOSM12), 1-12, 2012. 
11. Burke, R.D. Brace C.J., Hawley, J.G., Pegg I., Review of the system analysis of interactions between the thermal, lubricant, and combustion processes of diesel engines, $P$. .I Mech. Eng. D-J Aut. 224, doi:10.1234/0954407JAUTO1301.

12. Caresana, F., Bilancia, M., Bartolini C.M., "Numerical method for assessing the potential of smart engine thermal management: Application to a medium-upper segment passenger car", Appl. Therm. Eng. 31(16), 35593568, 2011, doi: 10.1016/j.applthermaleng.2011.07.017.

13. Lehner, C., Parker, G., Arici, O., Johnson, J., "Design and Development of a Model Based Feedback Controller Cooling System for Heavy Duty Diesel Truck Applications Using a Vehicle Engine Cooling System Simulation, SAE Technical Paper 2001-01-0336, 2001, doi: 10.4271/200101-0336.

14. Chalgren Jr., R.D., Allen, D.J., "Light Duty Diesel Advanced Thermal Management", SAE Technical Paper 2005-01-2020, 2005, doi: 10.4271/2005-01-2020.

15. Dimopoulos, P., Bacha, C., Soltica, P., Boulouchos, K., "Hydrogen-natural gas blends fuelling passenger car engines: Combustion, emissions and well-to-wheels assessment", Int. J. Hydrogen Energ. 33(23), 7224-7236, 2008, doi: 10.1016/j.ijhydene.2008.07.012.

16. Tauzia, X., Maiboom, A., "Experimental study of an automotive Diesel engine efficiency when running under stoichiometric conditions", Appl. Energ. 105, 116-124, 2013,doi:10.1016/j.energy.2012.12.034.

17. Osada, H., Uchida, N., Shimada, K., Aoyagi, Y., "Reexamination of Multiple Fuel Injections for Improving the Thermal Efficiency of a Heavy-Duty Diesel Engine", SAE Technical Paper 2013-01-0909, 2013,doi: 10.4271/2013-01-0909.

18. Sanli, A., Ozsezen A.N., Kilicaslan, I., Canakci, M., "The influence of engine speed and load on the heat transfer between gases and in-cylinder walls at fired and motored conditions of an IDI diesel engine", ", Appl. Therm. Eng. 28(11-12),1395-1404, 2008, doi: 10.1016/j.applthermaleng.2007.10.005.

19. Taymaz, i., "An experimental study of energy balance in low heat rejection diesel engine", Energy 31 (2-3) 364-371 2006, doi:10.1016/ j.energy.2005.02.004.

20. Morawitz, U., Mehring, J., Schramm, L., "Benefits of Thermal Spray Coatings in Internal Combustion Engines, with Specific View on Friction Reduction and Thermal Management", SAE Technical Paper 2013-01-029, 2013.

21. Serrano, J.R., Olmeda, P., Tiseira, A., García-Cuevas, L.M., "Importance of Mechanical Losses Modeling in the Performance Prediction of Radial Turbochargers under Pulsating Flow Conditions", SAE Technical Paper 201301-0577, 2013, doi: 10.4271/2013-01-0577.

22. Mills, R., Avan, E.Y., Dwyer-Joyce, R., "Measuring Lubricant Films at the Piston-Cylinder Contact: An Overview of Current Technologies with Focus on Ultrasound", SAE Technical Paper 2013-01-0294, 2013, doi 10.4271/2013-01-0294.

23. Taraza, D., Henein, N., "Friction Losses in Multi-Cylinder Diesel Engines", SAE Technical Paper Series 2000-010921, 2000.

24. Benajes, J. et al., "Analysis of the combustion process, pollutant emissions and efficiency of an innovative 2stroke HSDI engine designed for automotive applications", Appl. Therm. Eng., 58(1-2), 181-193, doi: 10.1016/j.applthermaleng.2013.03.050
25. Smith, L.A., Preston, W.H., Dowd, G., Taylor, O., Wilkinson, K.M., "Application of a First Law Heat Balance Method to a Turbocharged Automotive Diesel Engine", SAE Technical Paper 2009-01-2744, 2012, doi: 10.4271/2009-01-2744.

26. Ajav, E.A., Bachchan Singhb, Bhattacharya, T.K., "Thermal balance of a single cylinder diesel engine operating on alternative fuels", Ener. Convers. Manage. , 41 (14), 1533-1541, 2000, doi: 10.1016/S01968904(99)00175-2.

27. Abedin, M.J., Masjuki, H.H., Kalam, M.A., Sanjid, A., Ashrafur Rahman S.M., Masum, B.M., "Energy balance of internal combustion engines using alternative fuels", Renew. Sust. Energ. Rev. 26, 20-33, 2013.

28. Rakopoulos, C.D., Giakoumis, E.G., "Second-law analyses applied to internal combustion engines operation", Prog. Energ. Combust. 32(1), 2-47, 2006, doi: 10.1016/j.pecs.2005.10.001.

29. Annand, W.J.D., "Heat transfer in the cylinders of reciprocating internal combustion engines", P. I. Mech. Eng., 177, 973-990, 1963.

30. Morel, T., Keribar, R., "Heat radiation in DI diesel engines", SAE Technical Paper Series 860445, 1986.

31. Woschni, G., "A universally applicable equation for the instantaneous heat transfer coefficient in the internal combustion engine", SAE Technical Paper 670931, 1967.

32. Woschni, G., "Die Berechnung der Wandverluste und der thermischen Belastung der Bauteile von Dieselmotoren", MTZ 31/12, 491-499, 1970.

33. Torregrosa, A.J., Olmeda, P., Degraeuwe, B., Reyes, M., "A concise wall temperature model for DI Diesel engines", Appl. Therm. Eng. 26(11-12), 1320-1327, 2006, doi: 10.1016/j.applthermaleng.2005.10.021.

34. Torregrosa, A.J., Broatch, A., Olmeda, P., Martín, J., "A contribution to film coefficient estimation in piston cooling galleries", Exp. Therm. Fluid. Sci. 34(2), 142-51, 2010, doi: 10.1016/j.expthermflusci.2009.10.003.

35. Torregrosa, A.J., Olmeda, P., Martín, J., Romero, C., "A tool for predicting the thermal performance of a diesel engine", Heat Transfer Eng. 32(1), 891-904, 2011, doi: 10.1080/01457632.2011.548639.

36. Payri, F., Galindo, J., Martín, J., Arnau, F..J., "A simple model for predicting the trapped mass in a DI Diesel engine", SAE Technical Paper 2007-01-0494, 2007, doi: 10.4271/2007-01-0494.

37. Holmberg, K., Andersson, P., Erdemir, A., "Global energy consumption due to friction in passenger cars", Tribol. Int. 47, 221-234, 2012, doi: 10.1016/j.triboint.2011.11.022.

38. Payri F, Margot X, Gil A, Martín J., "Computational study of the heat transfer to the walls of a DI diesel engine", SAE Technical Paper Series 2005-01-0210, 2005.

39. Payri, F., Margot, X., Gil, A., Martín, J., "Prediction of heat transfer to the walls in DI diesel engines", Proceedings of the 2nd EACC, 2005.

40. Dec, J.E., "A conceptual model of DI diesel combustion based on laser sheet imaging", SAE Technical Paper Series 970873, 1997.

41. Arrègle, J., López, J.J., Martín, J., Mocholí, E.M., "Development of a Mixing and Combustion ZeroDimensional Model for Diesel Engines", SAE Technical Paper 2006-01-1382, 2012, doi: 10.4271/2006-01-1382.

42. Monin, C., "Characterization of the soot formation process in a low temperature diffusive flame in a Diesel engine" (in spanish), PhD Thesis, Universitat Politècnica de València, 2009. 
43. Lopez, J.J. et al., "A Soot Radiation Model for Diesel Sprays", SAE Technical Paper 2012-01-1069, 2012, doi: 10.4271/2012-01-1069.

44. Dolz, V., "Transmisión de calor en motores alternativos: aplicación al aprovechamiento energético de los gases de escape", Ed Reverté, 2011, ISBN: 9788429147155.

45. Depcik, C., Assanis, D., "A Universal Heat Transfer Correlation for Intake and Exhaust Flows in a SparkIgnition Internal Combustion Engine", SAE Technical Paper 2002-01-0372, 2002, doi: 10.4271/2002-01-0372.

46. Caton, J.A., "Comparisons of Thermocouple, TimeAveraged and Mass-Averaged Exhaust Gas Temperatures for a Spark-Ignited Engine", SAE Technical Paper 820050, 1982.

47. Reyes, M. "Heat transfer model for the exhaust manifolds of a reciprocating engine" (in spanish), PhD Thesis, Universitat Politècnica de València, 1994.

48. Cho, S., Cho, S.W., Choi, S.M., Bae, C.S., "Frictional modes of barrel shaped piston rings under flooded lubrication". Tribol. Int. 33 (8) 545-551, 2000, doi: 10.1016/S0301-679X(00)00103-1.

49. Taylor, C.M., "Engine Tribology", Elsevier, 1993,.

50. Cameron, A., "Basic Lubrication Theory", Ellis Horwood, 1984.

51. Comfort., A., "An Introduction to Heavy-Duty Diesel Engine Frictional Losses and Lubricant Properties Affecting Fuel Economy", SAE Technical Paper 2003-013225, 2003, doi: 10.4271/2003-01-3225.

52. Teodorescu, M., Taraza, D., Heneim, N., "Simplified Elasto-Hydrodynamic Friction Model of the Cam-Tappet contact", SAE Technical Paper, 2003-01-0985, 2003, doi: 10.4271/2003-01-0985.

53. Payri F., Molina S., Martín J., Armas O., "Influence of measurement errors and estimated parameters on combustion diagnosis", Applied Therm. Eng. 26 (2-3), 226236, 2006, doi:10.1016/j.applthermaleng.2005.05.006.

54. Martín, J., "Diagnóstico de la combustión en motores Diesel de inyección directa" (in spanish), Ed. Reverté, 2012, isbn: 978-84-291-4717-9.

55. Kouremenos, D.A., Rakopoulos, C.D., Hountalas, D.T., Zannis, T. K., "Development of a Detailed Friction Model to Predict Mechanical Losses at Elevated Maximum Combustion Pressures", SAE Technical Paper 2001-010333, 2001.

\section{Contact Information}

Dr. Jaime Martín

CMT- Motores Térmicos, Universitat Politècnica de València Camino de Vera s/n, 46022 Valencia (Spain)

Phone:+ 34963877650

e-mail: jaimardi@mot.upv.es

web: www.cmt.upv.es

\section{Acknowledgments}

The support of the Universitat Politècnica de València (PAID06-09) and Generalitat Valenciana (GV/2010/045) is greatly acknowledged. 


\section{Abbreviations}

Cl

GEB

HT

ICE

SI

TDC
Compression Ignition

Global Energy Balance

Heat Transfer

Internal Combustion

Engine

Spark Ignition

Top Dead Centre 